\title{
Luminescence mechanism in doubly Gd,Nd-codoped fluoride crystals for VUV scintillators
}

\author{
$\underline{\text { Jan Pejchal }}^{\mathrm{a}}{ }^{\mathrm{b}}$, Kentaro Fukuda $^{\mathrm{c}}$, Vladimir Babin ${ }^{\mathrm{b}}$, Shunsuke Kurosawa ${ }^{\mathrm{a}, \mathrm{d}}$, Yuui Yokota ${ }^{\mathrm{a}}$, Akira \\ Yoshikawa $^{\mathrm{a}, \mathrm{d}}$, Martin Nikl ${ }^{\mathrm{b}}$
}

a NICHe, Tohoku University, 6-6-10 Aoba, Aramaki, Aoba-ku, Sendai, 9808579, Japan

${ }^{\mathrm{b}}$ Institute of Physics AS CR,Cukrovarnicka 10, Prague 6,16200, Czech Republic

${ }^{\mathrm{c}}$ Tokuyama Corporation, Kasumigaseki Common Gate West Tower 2-1, Kasumigaseki 3-chome, Chiyoda-ku, Tokyo 1008983, Japan

${ }^{\mathrm{d}}$ Institute for Materials Research,2-1-1 Katahira, Aoba-ku, Sendai, 9808577, Japan

Email pejchalj@imr.tohoku.ac.jp

\section{Abstract}

The Nd-doped, Gd-doped and doubly Nd,Gd-codoped $\mathrm{BaLu}_{1.2} \mathrm{Y}_{0.8} \mathrm{~F}_{8}$ (BaLuYF) and $\mathrm{LuF}_{3}$ single crystals were grown by micro-pulling-down method. Their photoluminescence, radioluminescence and alpha-ray-excited pulse-height spectra were studied in the vacuum-ultra-violet (VUV) region to confirm their possible application as fast VUV scintillators. Complementary photoluminescence measurements in the ultra-violet/ visible spectral region were performed as well. The possibility of scintillation performance improvement by Gd codoping was tested. The overall scintillation efficiency of BaLuYF:Nd1\% was comparable to that of the $\mathrm{LaF}_{3}: \mathrm{Nd} 8 \%$ reference sample and only slight improvement was observed after Gd1\% codoping. The positive effect of Gd codoping was confirmed for higher dopant concentrations. This was explained by an energy transfer from the high-energy $\mathrm{Gd}^{3+}$ $4 \mathrm{f}^{2} \mathrm{G}(0)_{7 / 2}$ level to the $\mathrm{Nd}^{3+} 5 \mathrm{~d}$ state. On the other hand, pulse -height spectra showed degradation of the light yield under alpha-ray excitation, which was explained by introduction of slow components due to Gd codoping. On the other hand, no positive effect of Gd codoping was found for the overall scintillation efficiency of $\mathrm{Nd}$-doped $\mathrm{LuF}_{3}$, despite the same energy transfer process was confirmed. Slight improvement of the light yield under alpha-ray excitation was confirmed.

Keywords: barium-lutetium-yttrium fluoride, lutetium fluoride; scintillator; VUV luminescence

\section{Introduction}

Scintillators materials find their application in radiation detectors in several fields, such as medical imaging, security scanning, nuclear physics or astronomy. Requirement of very fast response with a scintillation decay time of several nanoseconds in some of the applications (nuclear physics applications or high-frame-rate imaging) triggered the search for new material systems. The $\mathrm{Nd}^{3+}-$ 
doped wide-band-gap fluorides emitting in the vacuum-ultra-violet (VUV) region were considered as the candidate materials [1-3]. Since the decay time of the rare earth $5 \mathrm{~d}-4 \mathrm{f}$ emission is proportional to the emission wavelength as $\tau \sim \lambda^{3}[7]$, the $\mathrm{Nd}^{3+} 5 \mathrm{~d}-4 \mathrm{f}$ VUV emission has the decay time of several nanoseconds. Other rare-earth luminescence ions emitting at even shorter wavelengths, such as $\mathrm{Tm}^{3+}$ or $\mathrm{Er}^{3+}$, can be considered as well [4]. When coupled to the contemporary fast VUV photodetectors such as gas electron multiplier (GEM) with micro-pixel chamber or a photomultiplier (PMT) with CsIcoated photocathode $[5,6]$, fast position-sensitive detection system can be obtained.

The first studied VUV scintillator was the Nd-doped $\mathrm{LaF}_{3}[1-3]$ with the $\mathrm{Nd}^{3+} 5 \mathrm{~d}-4 \mathrm{f}$ luminescence at $175 \mathrm{~nm}$ and fast decay time of 6-9 ns. It was proved that its scintillation performance is high enough for imaging with multiwire chamber [1] and its suitability for imaging applications were confirmed also in the recent study employing GEM and micro-pixel chamber [8]. In our research we choose this material as a reference.

Another material was Nd-doped $\mathrm{BaY}_{2} \mathrm{~F}_{8}$ studied also by some of us [10]. The $\mathrm{Nd}^{3+} 5 \mathrm{~d}-4 \mathrm{f}$ emission is shifted to longer wavelengths at $186 \mathrm{~nm}$ and therefore its decay time is prolonged to some $15 \mathrm{~ns}$. Admixture of $\mathrm{Lu}$ into the $\mathrm{BaY}_{2} \mathrm{~F}_{8}$ matrix and concentration optimization led to new material $\mathrm{BaLu}_{1.2} \mathrm{Y}_{0.8} \mathrm{~F}_{8}$ (BaLuYF). The overall scintillation efficiency of the Nd-doped BaLuYF was as high as that of $\mathrm{LaF}_{3}: \mathrm{Nd}$ [12], also partially due to increased density resulting from the $\mathrm{Lu}$ admixture.

Very favorable scintillation properties in the group of the VUV-emitting fluorides were found for $\mathrm{Nd}$ doped $\mathrm{LuF}_{3}$, such as very high overall scintillation efficiency exceeding several times that of $\mathrm{LaF}_{3}: \mathrm{Nd}$ [14], emission peaking at around $180 \mathrm{~nm}$, the scintillation response with a leading decay time of $8 \mathrm{~ns}$, high density of $8.3 \mathrm{~g} / \mathrm{cm}^{3}$ resulting in high stopping power for gamma-ray detection and so on. The scintillation properties were reported also for the high-quality Czochralski-grown single crystal [15].

Attempts to improve the scintillation efficiency by codoping of other VUV-emitting rare earth ions such as $\mathrm{Er}^{3+}$ or $\mathrm{Tm}^{3+}$ were also performed by some of us. In most of the fluoride matrices the $5 \mathrm{~d}-4 \mathrm{f}$ emission spectrum of $\mathrm{Er}^{3+}$ or $\mathrm{Tm}^{3+}$ overlaps with the excitation spectrum of $\mathrm{Nd}^{3+}$ and energy transfer is therefore possible. The energy transfer from $\mathrm{Er}^{3+}$ to $\mathrm{Nd}^{3+}$ was successfully proved in the $\mathrm{Er}^{3+}$ co-doped $\mathrm{BaY}_{2} \mathrm{~F}_{8}: \mathrm{Nd}$ [11]. Slight improvement of the overall scintillation efficiency by the energy transfer from the $\mathrm{Tm}^{3+}$ codoping ions was observed also in the $\mathrm{BaY}_{2} \mathrm{~F}_{8}: \mathrm{Nd}$ [17], $\mathrm{BaLu}_{2} \mathrm{~F}_{8}: \mathrm{Nd}$ [13] and BaLuYF:Nd [12] single crystals.

Recently, improvement of scintillation properties by $\mathrm{Gd}^{3+}$ codoping was observed for the $\mathrm{LiLuF}_{4} \mathrm{Nd}$ VUV scintillator [18]. However, no detailed explanation about this phenomenon was given and and it was only noted that there the energy transfer the highest $\mathrm{Nd}^{3+} 5 \mathrm{~d}$ state is improved in the presence of $\mathrm{Gd}^{3+}$. At the same time, the energy transfer from the $\mathrm{Nd}^{3+} 5 \mathrm{~d}$-states to the $\mathrm{Gd}^{3+} 4 \mathrm{f}$-ones was proved. Possible energy transfer from the $\mathrm{Gd}^{3+} 4 \mathrm{f}$-levels towards the $\mathrm{Nd}^{3+} 4 \mathrm{f}$-levels was suggested. It can be interesting to test the improvement of the scintillation efficiency of the other Nd-doped fluoride-based VUV scintillation materials by Gd-codoping.

The aims of this work are to study the luminescence and scintillation properties of the doubly Gd,Nd- 
doped $\mathrm{BaLuYF}$ and $\mathrm{LuF}_{3} \mathrm{VUV}$ scintillators and investigate the possibility of improvement of their performance by Gd codoping and sketch the possible luminescence mechanism.

\section{Experimental}

Fluoride powders of $4 \mathrm{~N}$ purity from Stella Chemifa Co. Ltd. were used as starting materials. To grow the BaLuYF crystals, the mixture of the $\mathrm{BaF}_{2}, \mathrm{LuF}_{3}, \mathrm{YF}_{3}, \mathrm{NdF}_{3}$ and/or $\mathrm{GdF}_{3}$ powders was used. The samples with following dopants and concentrations (molar percents) were prepared: $\mathrm{Nd} 1 \%, \mathrm{Gd} 1 \%$, $\mathrm{Nd} 5 \%$, Gd5\%, and doubly doped Gd1\%Nd1\%, Gd5\%Nd5\% and $\mathrm{Gd} 20 \% \mathrm{Nd} 5 \%$. The dopants substituted for the $\mathrm{Lu}^{3+}$ ion.

Crystal growth was carried out with graphite crucible under $\mathrm{Ar}+\mathrm{CF}_{4}$ (9:1) atmosphere using the micro-pulling-down ( $\mu$-PD) furnace with vacuum-tight systems tailored for fluoride growth, for details see [16]. The undoped $\mathrm{BaY}_{2} \mathrm{~F}_{8}$ was used as the seed crystal. The crystal melts congruently at around $950^{\circ} \mathrm{C}$. The crystal was pulled out at a pulling speed of $0.1 \mathrm{~mm} / \mathrm{min}$. The as-grown crystals were $2 \mathrm{~mm}$ in diameter and $50 \mathrm{~mm}$ in length.

To grow the $\mathrm{LuF}_{3}$ crystals, the mixture of $\mathrm{LuF}_{3}$ and $\mathrm{NdF}_{3}$ and/or $\mathrm{GdF}_{3}$ was used. The samples with the following composition were grown: $\mathrm{Nd} 1 \%, \mathrm{Gd} 1 \%, \mathrm{Nd} 5 \%$, and doubly doped $\mathrm{Gd} 1 \% \mathrm{Nd} 1 \%$ and Gd5\%Nd5\%.

The crystals were grown with the same micro-pulling-down setup as described above.

$43 \mathrm{~mol} \% \mathrm{LiF}$ was added to each charge to diminish the melting point of the mixture below the phase transition temperature. The phase transition occurs some $250^{\circ} \mathrm{C}$ below the melting point which is around $1160^{\circ} \mathrm{C}$. The as grown crystals were of $2.0-2.5 \mathrm{~mm}$ in diameter and $5-10 \mathrm{~mm}$ in length. The surface of the crystals was a bit rough and opaque, but the crystals were transparent inside.

The as-grown BaLuYF and $\mathrm{LuF}_{3}$ crystals were cut along the growth axis and polished with $0.3 \mu \mathrm{m}$ diamond paste. Obtained plates with the dimension of $2.0 \times 5.0-10.0 \times 1.0 \mathrm{~mm}^{3}$ were used for optical experiments.

To identify the phase, powder X-ray diffraction analysis (XRD) was carried out in the $2 \theta$ range from $20^{\circ}$ to $80^{\circ}$ using the RIGAKU diffractometer (RINT2000).

Transmittance, photoluminescence and radioluminescence (RL) emission spectra were obtained at the Spectrofluorometer (Bunko-keiki Co. Ltd.) using VUV sensitive CCD (Andor) and $\mathrm{D}_{2}$ steady-state lamp as an excitation source. An X-ray tube operated at $50 \mathrm{kV}$ and $20 \mathrm{~mA}$ with $\mathrm{Cu}$ anode has been used for the X-ray excitation. Measurements were not corrected for experimental distortions, which include the CCD sensitivity and monochromator throughput that are spectrally dependent. Such correction has not been made as no calibrated VUV emission source is available so far to enable

precise correction curve measurement. The experimental distortions can influence the spectra in a way that mutual intensities of particular peaks can be different in our spectra and in reality. However, mutual comparisons of the intensities are possible due to flat spectral sensitivity of the CCD in the 170-180 nm region. The sample dimensions and experiment geometry was kept strictly the same, so 
that the peak intensities at the same wavelengths are mutually comparable in an absolute way for different samples, except for the Nd-doped one due to its smaller size. The metallic mask enabled light collection from the same area of each sample. To compare the radioluminescence (RL) intensity, RL of high quality $\mathrm{LaF}_{3} \mathrm{Nd} 8 \%$ standard sample was measured.

The measurements of the photoluminescence excitation spectra in the VUV emission region were performed using synchrotron radiation at SUPERLUMI station of the DORIS positron storage ring in HASYLAB, DESY, Hamburg [19]. The spectra were corrected for detector sensitivity and monochromator throughput using correction curve obtained from measurement of excitation spectrum of sodium salicylate for its $400 \mathrm{~nm}$ emission peak. Due to technical issues it was impossible so far to measure the decay kinetics in VUV region which would help to better clarify the energy transfer and luminescence processes at high excitation energies. Such experiments are planned for the future.

Complementary measurements in the ultra-violet/visible (UV/VIS) region were performed with custom-made Horiba 5000M series spectrofluorometer under Xe-lamp excitation. The true decay times were extracted by a deconvolution procedure with instrumental response using SpectraSolve software (Ames Photonics Inc.).

To measure the light output, the crystal samples were excited with alpha rays from a ${ }^{241} \mathrm{Am}(5.5 \mathrm{MeV})$ source. The scintillation photons were detected by a photomultiplier (PMT, R8778, Hamamatsu), and then the signal from the PMT was amplified, shaped with a shaping time of $500 \mathrm{~ns}$ (572A, ORTEC), and read out with a multi-channel analyzer (Pocket MCA 8000A, AMPTEK). After obtaining the pulse height spectra, the channel positions of the full absorption peak was estimated. Similarly as for X-rayexcited $\mathrm{RL}$ spectra, the $\mathrm{LaF}_{3}: \mathrm{Nd} 8 \%$ was measured as a reference. The alpha-ray source was used as the small size of the crystals grown by the micro-pulling-down method did not allow measurements under gamma-ray excitation.

\section{Results and discussion}

\subsection{BaLuYF crystals}

Transparent and crack-free Nd-doped, Gd-doped, and doubly Gd,Nd BaLuYF crystals were successfully grown (not shown here). The XRD analysis confirmed the monoclinic structure (space group $\mathrm{C} 2 / \mathrm{m}$ ) similar to that of $\mathrm{BaY}_{2} \mathrm{~F}_{8}$, but with slightly smaller lattice constant due to smaller ionic radii of $\mathrm{Lu}^{3+}$ when compared to that of $\mathrm{Y}^{3+}$.

Also the transparent and crack-free Nd-doped, Gd-doped, and doubly Gd,Nd-doped $\mathrm{LuF}_{3}$ crystals were successfully grown (not shown here). Just the size of the Nd1\% sample was quite small (around $3 \mathrm{~mm}$ in length) due to crystal growth difficulties caused probably by more significant difference between $\mathrm{Lu}^{3+}$ and $\mathrm{Nd}^{3+}$ cation radii. The XRD analysis confirmed the low-temperature orthorhombic $\mathrm{LuF}_{3}$ phase and the diffraction peaks corresponded to the 32-0612 JCPDS chart.

The comparison of the radioluminescence spectra in the VUV/UV region under X-ray excitation for 
the $\mathrm{Gd} 1 \%, \mathrm{Nd} 1 \%$ and $\mathrm{Gd} 1 \% \mathrm{Nd} 1 \%$ BaLuYF single crystals is shown in the figure 1 together with the spectrum for the $\mathrm{LaF}_{3}: \mathrm{Nd} 8 \%$ reference crystal with optimized $\mathrm{Nd}$ concentration. For both the Ndcontaining BaLuYF samples, the $\mathrm{Nd}^{3+}$ emission related to the transition from the $5 \mathrm{~d}$-state to the ${ }^{4} \mathrm{I}$ multiplet is situated around $185 \mathrm{~nm}$. Transitions from the $5 \mathrm{~d}$-state to the higher ${ }^{4} \mathrm{~F}$ or ${ }^{4} \mathrm{G}$ multiplets can be observed at 235 and $270 \mathrm{~nm}$, respectively. The same can be observed for the $\mathrm{LaF}_{3}: \mathrm{Nd}$ reference but the peaks are shifted towards shorter wavelengths due to decreased crystal field in the $\mathrm{LaF}_{3}$ matrix. The intensity of the $\mathrm{Nd}^{3+} 5 \mathrm{~d}-4 \mathrm{f}$ emission peak at $185 \mathrm{~nm}$ for the BaLuYF:Nd1\% is lower than that for the $\mathrm{LaF}_{3}: \mathrm{Nd}$ reference. On the other hand, the BaLuYF:Gd1\%Nd1\% sample slightly outperforms the reference scintillator, which can be a sign of a positive effect of $\mathrm{Gd}$ codoping on the overall scintillation efficiency in the VUV region. For the BaLuYF:Gd1\% sample, obviously, only the intense $4 \mathrm{f}-4 \mathrm{f} \mathrm{Gd}^{3+}$ lines can be observed at 250, 275 and $311 \mathrm{~nm}$. The can be ascribed to the ${ }^{6} \mathrm{D}_{9 / 2} \rightarrow{ }^{8} \mathrm{~S}_{7 / 2}$, ${ }^{6} \mathrm{I}_{9 / 2}\left({ }^{6} \mathrm{I}_{7 / 2}\right) \rightarrow{ }^{8} \mathrm{~S}_{7 / 2}$ and ${ }^{6} \mathrm{P}_{7 / 2} \rightarrow{ }^{8} \mathrm{~S}_{7 / 2}$ transitions, respectively. The same transitions are observed also in the doubly-doped BaLuYF:Gd1\%Nd1\%, but their intensities are significantly lower than those in the Ndfree BaLuYF:Gd1\% sample. Thus, there can be a mechanism preventing the excitation energy from being transferred towards the $\mathrm{Gd}^{3+} 4 \mathrm{f}-$ levels, or there can be a process withdrawing the energy from the $\mathrm{Gd}^{3+} 4 \mathrm{f}$-levels.

It is worth noticing that the $\mathrm{Nd}^{3+}$ concentration in the $\mathrm{LaF}_{3}: \mathrm{Nd}$ reference is 8 times higher when compared to the above discussed BaLuYF samples. So, there is a question how is the influence of the dopants concentration on the overall scintillation efficiency of the BaLuYF scintillation material. The comparison of the radioluminescence spectra for the $\mathrm{Nd} 5 \%, \mathrm{Gd} 5 \% \mathrm{Nd} 5 \%$ and $\mathrm{Gd} 20 \% \mathrm{Nd} 5 \%$ samples is shown in the figure 2 together with the radioluminecence spectrum for the $\mathrm{LaF}_{3}: \mathrm{Nd} 8 \%$ reference. The spectrum for the BaLuYF:Nd5\% sample shows that the increase of the Nd concentration does not bring significant improvement of the overall scintillation efficiency, though some slight increase in the $\mathrm{Nd}^{3+} 5 \mathrm{~d}-4 \mathrm{f}$ emission intensity can be observed. However, addition of $5 \%$ of Gd leads to significant increase of the $\mathrm{Nd}^{3+} 5 \mathrm{~d}-4 \mathrm{f}$ emission peak at $185 \mathrm{~nm}$. The BaLuYF:Gd5\%Nd5\% outperforms the Nd5\% sample and the $\mathrm{LaF}_{3}: \mathrm{Nd} 8 \%$ by a about a factor of 2 . This is an apparent proof that $\mathrm{Gd}^{3+}$ codoping improves the scintillation efficiency for higher dopant concentration. It will be shown later that there is an energy transfer mechanism from the $\mathrm{Gd}^{3+} 4 \mathrm{f}$ levels to the $\mathrm{Nd}^{3+} 5 \mathrm{~d}$ ones, as was suggested in [18]. Further increase of the $\mathrm{Gd}$ concentration to $20 \%$ decreases the the intensity of the $\mathrm{Nd}^{3+} 185 \mathrm{~nm}$ peak, most probably due to increased energy migration over the $\mathrm{Gd}^{3+}$ ions and consequent concentration quenching. This idea is also supported by the fact that the intensities of the $\mathrm{Gd}^{3+} 4 \mathrm{f}-4 \mathrm{f}$ lines almost do not increase in the BaLuYF:Gd20\%Nd5\% with respect to the Gd5\%Nd5\% sample. The decrease of the $\mathrm{Nd}^{3+} 5 \mathrm{~d}-4 \mathrm{f}$ emission intensity in the presence of large amount of Gd can be also explained by an increased probability of an energy back-transfer from the $\mathrm{Nd}^{3+} 5 \mathrm{~d}$-levels to the $\mathrm{Gd}^{3+} 4 \mathrm{f}$ ones, which was also concluded in [18].

Let us focus on clarification of the energy transfer from the $\mathrm{Gd}^{3+}$ ions to the $\mathrm{Nd}^{3+}$ ones. As described in the introduction, in the $\mathrm{Er}^{3+}$ and $\mathrm{Nd}^{3+}$-doped crystals, the $5 \mathrm{~d}-4 \mathrm{f} \mathrm{Er}^{3+}$ emission in the VUV region 
overlaps with the $\mathrm{Nd}^{3+} 4 \mathrm{f}-5 \mathrm{~d}$ absorption making the energy transfer possible. There is a question what is the mechanism of the energy transfer and if there is such a suitable emission in the VUV region for the $\mathrm{Gd}^{3+}$ ion. Such an emission was indeed observed for the first time. Figure 3 shows the emission spectrum for the BaLuYF:Gd5\% sample under $120 \mathrm{~nm}$ excitation, which corresponds to the band-toband transition. Such an excitation simulates the very last stage of the scintillation process, when the electron-hole pair is transferred to the dopant, in this case the $\mathrm{Gd}^{3+}$ ion. The spectrum is quite noisy due to lower intensity of the deuterium excitation lamp at $120 \mathrm{~nm}$, but two peaks can be still clearly observed at $157 \mathrm{~nm}$ and $147 \mathrm{~nm}$. The $157 \mathrm{~nm}$ peak is a scattered stray light always observed in our apparatus, however, the sharp line at $147 \mathrm{~nm}$ is a real luminescence that was ascribed to the $\mathrm{Gd}^{3+}$ ${ }^{2} \mathrm{G}(0)_{7 / 2} \rightarrow{ }^{8} \mathrm{~S}_{7 / 2}$ transition and has never been reported before. Taking into account the $\mathrm{Gd}^{3+}$ complicated level structure at high energies [20], one can suggest that there should be an inevitable energy leak from the ${ }^{2} \mathrm{G}(0)_{7 / 2}$ to the lower lying ${ }^{2} \mathrm{Q}_{23 / 2}$ level separated by some $520 \mathrm{~cm}^{-1}$ gap and this would lead to quenching of the radiative transition from the ${ }^{2} \mathrm{G}(0)_{7 / 2}$ level. On the other hand, the total orbital and angular momentum quantum numbers of the ${ }^{2} \mathrm{Q}_{23 / 2}$ level are unusually high and the transition from the ${ }^{2} \mathrm{G}(0)_{7 / 2}$ can be strongly forbidden enabling the radiative transition from the ${ }^{2} \mathrm{G}(0)_{7 / 2}$ state to the ${ }^{8} \mathrm{~S}_{7 / 2}$ ground state (or other higher-lying states) responsible for the $147 \mathrm{~nm}$ emission [21].

Figure 4 shows the excitation spectrum of the $185 \mathrm{~nm} \mathrm{Nd}^{3+} 5 \mathrm{~d}-4 \mathrm{f}$ emission measured with Superlumi station at DESY. The three broad peaks at 135,157 and $178 \mathrm{~nm}$ are due to transitions from the ${ }^{4} \mathrm{I}_{9 / 2}$ ground state to the splitted $5 \mathrm{~d}$ levels. The vertical line denotes the $147 \mathrm{~nm}$ wavelength, which is still located at the long-wavelength shoulder of the $135 \mathrm{~nm}$ excitation. This makes the overlap of the $\mathrm{Nd}^{3+}$ excitation spectrum with the $\mathrm{Gd}^{3+}{ }^{2} \mathrm{G}(0)_{7 / 2} \rightarrow{ }^{8} \mathrm{~S}_{7 / 2}$ radiative transition possible and satisfies the necessary condition for an energy transfer from the $\mathrm{Gd}^{3+}$ ion to the $\mathrm{Nd}^{3+}$ one.

Thus, we can conclude that the $\mathrm{Gd}^{3+}{ }^{2} \mathrm{G}(0)_{7 / 2} \rightarrow{ }^{8} \mathrm{~S}_{7 / 2}$ transition can really take place and can improve the energy transfer towards the $\mathrm{Nd}^{3+}$ ion, which leads to the increase of the BaLuYF:Nd overall scintillation efficiency. Moreover, this process probably causes the decrease of the $\mathrm{Gd}^{3+} 4 \mathrm{f}-4 \mathrm{f}$ emission intensity observed in the figure 1 in the spectrum for the BaLuYF:Gd1\%,Nd1\% sample. Significant part of the excitation energy from the $\mathrm{Gd}^{3+}$ ion is transferred to the $\mathrm{Nd}^{3+}$ ion before the $\mathrm{Gd}^{3+} 4 \mathrm{f}-4 \mathrm{f}$ luminescence can take place. On the other hand, energy transfer from the $\mathrm{Gd}^{3+} 4 \mathrm{f}$-level might introduce a slow component in the scintillation decay process. There is a question what is the decay time of the transition from the $\mathrm{Gd}^{3+2} \mathrm{G}(0)_{7 / 2}$ level, which might be also affected both by still possible nonradiative transition to the ${ }^{2} \mathrm{Q}_{23 / 2}$ level or by the energy transfer to the $\mathrm{Nd}^{3+}$ itself. As mentioned above, the decay kinetics measurement in the VUV region is planned for the future to verify these processes. Measurement of the pulse-height spectra using VUV-sensitive PMT might bring certain insight to the scintillation process in the VUV region. Comparison of the pulse-height spectra for the $\mathrm{Nd} 1 \%, \mathrm{Nd} 5 \%, \mathrm{Gd} 1 \% \mathrm{Nd} 1 \%$ and $\mathrm{Gd} 5 \% \mathrm{Nd} 5 \%$ BaLuYF samples together with the $\mathrm{LaF}_{3}: \mathrm{Nd} 8 \%$ reference sample is shown in the figure 5. Unlike for the X-ray-excited RL spectra, all the samples perform significantly worse than the $\mathrm{LaF}_{3}: \mathrm{Nd}$ reference, whose peak is the only one well resolved 
from the background. From the studied samples, the Nd5\% sample seems to have the highest light yield which overcomes the Gd5\%Nd5\% sample. Considering the 500 ns shaping time, these results could suggest that Gd codoping introduces slow components and most of the light is emitted beyond the 500 ns time gate.

One has also take into account that under gamma-ray the material might have different response and performance due to its much higher penetrability and smaller ionization density.

As stated for the BaLuYF:Gd20\%Nd5\% above and in [18], there can be an energy back-transfer from the $\mathrm{Nd}^{3+}$ levels to the $\mathrm{Gd}^{3+}$ ones, which can consist in overlapping of the other $\mathrm{Nd}^{3+} 5 \mathrm{~d}$ or $4 \mathrm{f}$ levels with the $\mathrm{Gd}^{3+} 4 \mathrm{f}$ ones. The comparison of the $\mathrm{Nd}^{3+} 5 \mathrm{~d}-4 \mathrm{f}$ photoluminescence emission spectrum under $147 \mathrm{~nm}$ excitation for the BaLuYF:Nd1\% sample with the transmittance spectrum for the BaLuYF:Gd20\% crystal is displayed in the figure 6. There is an apparent overlap of the $\mathrm{Nd}^{3+} 5 \mathrm{~d}^{-}{ }^{4} \mathrm{G}_{\mathrm{J}}$ transition with the $\mathrm{Gd}^{3+}{ }^{8} \mathrm{~S}_{7 / 2} \rightarrow{ }^{6} \mathrm{I}_{7 / 2},{ }^{6} \mathrm{I}_{9 / 2}$ absorption transitions around $270 \mathrm{~nm}$. This can be the main pathway of the energy back-transfer to the $\mathrm{Gd}^{3+}$ ions. Moreover, weaker $\mathrm{Gd}^{3+}$ transitions at 200 and

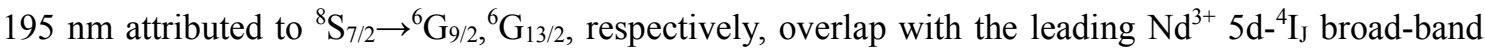
centered at $185 \mathrm{~nm}$. This pathway can also contribute to the energy back-transfer.

Reference [18] suggests an energy transfer from the lowest $\mathrm{Gd}^{3+}{ }^{6} \mathrm{P}_{7 / 2}$ level to the $\mathrm{Nd}^{3+}{ }^{2} \mathrm{~L}_{17 / 2}$ one in the $\mathrm{LiLuF}_{4}$ host. To test this hypothesis, we have measured photoluminescence decay kinetics of the $\mathrm{Gd}^{3+}$ ${ }^{6} \mathrm{P}_{7 / 2} \rightarrow{ }^{8} \mathrm{~S}_{7 / 2}$ transition at $311 \mathrm{~nm}$ under $306 \mathrm{~nm}$ direct excitation for the Gd1\% sample (figure $7 \mathrm{a}$ ), $\mathrm{Nd}^{3+}$ emission at $360 \mathrm{~nm}$ corresponding to the ${ }^{4} \mathrm{D}_{3 / 2} \rightarrow{ }^{4} \mathrm{I}_{9 / 2}$ transition under $275 \mathrm{~nm}$ excitation (ascribed to the $\mathrm{Nd}^{3+}{ }^{4} \mathrm{I}_{9 / 2} \rightarrow{ }^{2} \mathrm{H}_{11 / 2}$ transition [22]) for the $\mathrm{Nd} 1 \%$-only sample (figure $7 \mathrm{~b}$ ) and the same $\mathrm{Nd}^{3+}$ emission at $360 \mathrm{~nm}$ under $275 \mathrm{~nm}$ excitation for the $\mathrm{Nd}, \mathrm{Gd}$ sample (figure 7c). It is worth noting the $275 \mathrm{~nm}$ excitation also matches the $\mathrm{Gd}^{3+}{ }^{8} \mathrm{~S}_{7 / 2} \rightarrow{ }^{6} \mathrm{I}_{7 / 2}$ transition and the ${ }^{6} \mathrm{I}_{7 / 2}$ level can be also populated from the $\mathrm{Nd}^{3+} 5 \mathrm{~d}-{ }^{4} \mathrm{G}_{\mathrm{J}}$ transition under high-energy excitation as shown above. In the $\mathrm{Nd}^{3+}$ decay process under $275 \mathrm{~nm}$ excitation, the electron nonradiatively deexcites from the ${ }^{2} \mathrm{H}_{11 / 2}$ level to the ${ }^{4} \mathrm{D}_{3 / 2}$ one from which the luminescence takes place. The decay time of the $\mathrm{Gd}^{3+} 311 \mathrm{~nm}$ emission for the Gd-doped sample in the figure 7a is around $7.5 \mathrm{~ms}$ while that of the $360 \mathrm{~nm} \mathrm{Nd}^{3+}$ emission for the Nddoped sample in the figure $7 \mathrm{~b}$ is around $2 \mathrm{~ms}$. The decay curve of the $\mathrm{Nd}^{3+} 360 \mathrm{~nm}$ under $275 \mathrm{~nm}$ excitation for the Gd,Nd-doped sample clearly shows both $2 \mathrm{~ms}$ and slower $6.7 \mathrm{~ms}$ component and proofs the energy transfer from the $\mathrm{Gd}^{3+}$ ion to the $\mathrm{Nd}^{3+}$ one. Acceleration of this slow component is most probably the consequence of the energy transfer itself, which works as another energy-loss channel. Some part of the $\mathrm{Nd}^{3+}$ ions are still excited directly as the $\mathrm{Nd}^{3+} 2 \mathrm{~ms}$ component is still present. When the Gd,Nd sample was excited under $306 \mathrm{~nm}$, very similar result was obtained, which means that the $\mathrm{Nd}^{3+}$ ion is excited probably to the ${ }^{2} \mathrm{H}_{9 / 2}$ level from which again nonradiatively deexcites to the ${ }^{4} \mathrm{D}_{3 / 2}$ one and $360 \mathrm{~nm}$ luminescence takes place. The slow component in the $\mathrm{Nd}^{3+}$ decay is a proof that its ${ }^{2} \mathrm{~L}_{17 / 2}$ level is populated from the $\mathrm{Gd}^{3+}{ }^{6} \mathrm{P}_{7 / 2}$ one. Nonradiative transition from the ${ }^{2} \mathrm{~L}_{17 / 2}$ level to the ${ }^{4} \mathrm{D}_{3 / 2}$ one takes place. The the transition to the ground state yields the $360 \mathrm{~nm}$ emission. Decay kinetics of the $390 \mathrm{~nm}$ and $418 \mathrm{~nm} \mathrm{Nd}^{3+}$ emissions were tested under excitation into 
$\mathrm{Gd}^{3+}{ }^{6} \mathrm{P}$ multiplet, but the decay curves became more complicated. Further analysis, which is out of the scope of this article, needs to be done to clarify such processes. No schematic of the above described processes is given and the reader is referred to the figure 7 in [22] and related appendix.The scintillation mechanism in the doubly-doped BaLuYF:Gd,Nd scintillation crystal is summarized in the schematics shown in the figure 8 . The energy transfer processes related to the UV/VIS emitting $4 \mathrm{f}$ levels are omitted for simplicity. Thermalized electron-hole pairs can be captured directly on the $\mathrm{Nd}^{3+}$ luminescence center giving rise to the $5 \mathrm{~d}-4 \mathrm{f} \mathrm{Nd}^{3+}$ luminescence. Under direct photoluminescence excitation into the $\mathrm{Nd}^{3+} 4 \mathrm{f}-5 \mathrm{~d}$ bands of the BaLuYF:Nd1\% sample the $\mathrm{Nd}^{3+} 4 \mathrm{f}-4 \mathrm{f}$ emission intensities are very small, so we can consider the nonradiative energy leak from the $5 \mathrm{~d}$-levels to the $4 \mathrm{f}$ ones to be insignificant. A bit more intense $\mathrm{Nd}^{3+} 4 \mathrm{f}-4 \mathrm{f}$ peaks were observed under X-ray excitation, which would mean that they can be populated not only via the leak from the 5d-levels, but also from the excited host levels. The thermalized electron-hole pair can be captured also on the $\mathrm{Gd}^{3+}$ codoping ion, which can further de-excite via the $4 \mathrm{f}-4 \mathrm{f}$ luminescence or the energy can be transferred from the ${ }^{2} \mathrm{G}(0)_{7 / 2}$ level towards $\mathrm{Nd}^{3+} 5 \mathrm{~d}$ one. At the same time, when a transition from the $\mathrm{Nd}^{3+} 5 \mathrm{~d}$ level to the highest ${ }^{4} \mathrm{G}_{\mathrm{J}}$ multiplet takes place, the energy can be transferred to the $\mathrm{Gd}^{3+}{ }^{6} \mathrm{I}_{7 / 2}$ level. The thermalized electronhole pairs do not need to be necessarily captured only at the doping ions but can be captured also at the host levels giving rise for example to the above-mentioned increase of the $\mathrm{Nd}^{3+} 4 \mathrm{f}-4 \mathrm{f}$ luminescence intensity. The luminescence related to the host levels of undoped BaLuYF single crystal was reported for example in [12]. The host levels can be also involved in various quenching processes competing with the energy transfer towards the doping ions. These processes were also omitted for simplicity in the schematic in the figure 8 .

\section{2. $\mathrm{LuF}_{3}$ crystals}

The radioluminescence spectra under X-ray excitation for the $\mathrm{Gd} 1 \%$, Nd1\% and $\mathrm{Gd} 1 \% \mathrm{Nd} 1 \% \mathrm{LuF}_{3}$ single crystals are compared in the figure 9 together with the spectrum for the $\mathrm{LaF}_{3}: \mathrm{Nd} 8 \%$ reference crystal. Again, the $\mathrm{Nd}^{3+} 5 \mathrm{~d}-4 \mathrm{f}$ emission bands can be observed, but they are shifted towards shorter wavelengths due to weaker crystal field in $\mathrm{LuF}_{3}$ matrix. The leading $\mathrm{Nd}^{3+} 5 \mathrm{~d}-{ }^{4} \mathrm{I}_{\mathrm{J}}$ transition is situated at around $175 \mathrm{~nm}$. The $\mathrm{Gd}^{3+} 4 \mathrm{f}-4 \mathrm{f}$ bands are observed as well. In this case the most striking difference with respect to BaLuYF is that both Nd-containing samples significantly outperform the reference scintillator showing almost 8 times higher overall scintillation efficiency in the VUV region. This confirms observations reported in [15]. However, the intensity of the $\mathrm{Nd}^{3+} 5 \mathrm{~d}-4 \mathrm{f}$ emission is slightly lower for the doubly-doped Gd1\%Nd1\% sample. Further increase of dopant concentration leads to degradation of scintillation efficiency. The intensity of the leading $\mathrm{Nd}^{3+}$ emission at $175 \mathrm{~nm}$ decreases for the $\mathrm{LuF}_{3}: \mathrm{Nd} 5 \%$ crystal almost 3 times when compared to the $\mathrm{LuF}_{3}: \mathrm{Nd} 1 \%$ one, most probably due to concentration quenching. The leading $\mathrm{Nd}^{3+}$ emission for the $\mathrm{LuF}_{3}: \mathrm{Gd} 5 \% \mathrm{Nd} 5 \%$ reaches the same value as that for the $\mathrm{LaF}_{3}: \mathrm{Nd} 8 \%$ reference crystal (not shown here). We can conclude that the Gd co-

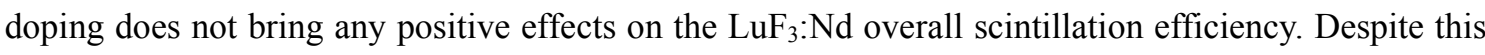


fact the energy transfer from the $\mathrm{Gd}^{3+}$ luminescence center towards the $\mathrm{Nd}^{3+}$ one can still work. The unusual luminescence ascribed to the $\mathrm{Gd}^{3+2} \mathrm{G}(0)_{7 / 2} \rightarrow{ }^{8} \mathrm{~S}_{7 / 2}$ transition at $147 \mathrm{~nm}$ can be also observed in the $\mathrm{LuF}_{3}$ sample under $120 \mathrm{~nm}$ (band-to-band) excitation (figure 10), similarly as for the Gd-doped BaLuYF one. The overlap of this emission with the excitation spectrum of the $\mathrm{Nd}^{3+} 5 \mathrm{~d}-4 \mathrm{f}$ VUV luminescence is also confirmed in the figure 11, where the vertical line indicates the $147 \mathrm{~nm}$ wavelength. Concerning other back-transfer processes from $\mathrm{Nd}^{3+}$ to $\mathrm{Gd}^{3+}$, the overlap of the $\mathrm{Nd}^{3+} 5 \mathrm{~d}-$ ${ }^{4} \mathrm{G}_{\mathrm{J}}$ transition with the $\mathrm{Gd}^{3+}{ }^{8} \mathrm{~S}_{7 / 2} \rightarrow{ }^{6} \mathrm{I}_{7 / 2},{ }^{6} \mathrm{I}_{9 / 2}$ absorption transitions already does not occur due to shift of the $\mathrm{Nd}^{3+}$ emission spectrum towards shorter wavelengths, which can be seen from the comparison of the photoluminescence emission spectrum under $149 \mathrm{~nm}$ excitation for $\mathrm{LuF}_{3}: \mathrm{Nd} 1 \%$ and transmittance spectrum for the $\mathrm{LuF}_{3}: \mathrm{Gd} 5 \% \mathrm{Nd} 5 \%$ (figure 12). In this case, there is an absorption line in the Gdcontaining sample around $185 \mathrm{~nm}$ tentatively ascribed to the $\mathrm{Gd}^{3+}{ }^{8} \mathrm{~S}_{7 / 2} \rightarrow{ }^{6} \mathrm{~F}_{9 / 2}$ transition which overlaps with the $\mathrm{Nd}^{3+} 5 \mathrm{~d}_{-}^{4} \mathrm{I}_{\mathrm{J}}$ transition. This can be the pathway of energy back-transfer from $\mathrm{Nd}^{3+}$ to $\mathrm{Gd}^{3+}$. It is also worth noting that the $\mathrm{Gd}^{3+}{ }^{6} \mathrm{P}_{7 / 2} \rightarrow{ }^{8} \mathrm{~S}_{7 / 2}$ emission at $311 \mathrm{~nm}$ was observed under $156 \mathrm{~nm}$ excitation into the $\mathrm{Nd}^{3+} 4 \mathrm{f}-5 \mathrm{~d}$ band in the $\mathrm{LuF}_{3}: \mathrm{Gd} 1 \% \mathrm{Nd} 1 \%$ crystal (not shown here). This also confirms that some back-transfer process takes place.

The comparison of the alpha-ray-excited pulse-height spectra for the $\mathrm{LuF}_{3}: \mathrm{Nd}_{1 \%}$ and $\mathrm{LuF}_{3}: \mathrm{Gd} 1 \% \mathrm{Nd} 1 \%$ crystals is compared in the figure 13. Due to the high ligh yield of the $\mathrm{LuF}_{3}$ crystals, the number of channels and the amplifier gain were chosen to be different from the measurements in the figure 5, that is why the position of the peak for the reference crystal is at different channel number. Interestingly, we can see not only that both of them significantly outperform the $\mathrm{LaF}_{3}: \mathrm{Nd} 8 \%$ reference, but the Gd-codoped sample performs slightly better than the Nd-only doped counterpart. This suggests that for low dopant concentrations around $1 \% \mathrm{Gd}^{3+}$ codoping improves the energy transfer towards $\mathrm{Nd}^{3+}$ centers and is fast enough not to introduce significant amounts of slow components. Further studies of time-resolved measurements are necessary to clarify this process and explain the discrepancy between the pulse-height spectra and X-ray excited RL. As already stated, one must keep in mind different penetration depth and ionization density of alpha particles and highenergy photons.

Enhancement of $\mathrm{Nd}^{3+} 4 \mathrm{f}-4 \mathrm{f}$ lines in the UV-visible region was observed in the presence of $\mathrm{Gd}$ in photoluminescence measurements (not shown here). This may also point to an energy transfer from $\mathrm{Gd}^{3+} 4 \mathrm{f}$ levels towards $\mathrm{Nd}^{3+} 4 \mathrm{f}$ ones, as suggested in [18] for $\mathrm{LiLuF}_{4}$ host and shown above for the BaLuYF crystals. Similar photoluminescence simple study to test the energy transfer between $\mathrm{Nd}^{3+}$ and $\mathrm{Gd}^{3+} 4 \mathrm{f}$ energy levels emitting in UV region was performed. Again, the decay kinetic of the Gd3+ $311 \mathrm{~nm}$ emission under $306 \mathrm{~nm}$ excitation was performed for the $\mathrm{LuF}_{3}: \mathrm{Gd} 1 \%$ sample yielding slightly longer decay time of $7.8 \mathrm{~ms}$. The decay time of the $360 \mathrm{~nm}$ emission for the $\mathrm{Nd}^{3+}$ emission under 275 $\mathrm{nm}$ and $306 \mathrm{~nm}$ excitations for the Nd-doped sample only was again around $2 \mathrm{~ms}$ (not shown here). On the other hand, when the $\mathrm{Nd}^{3+} 360 \mathrm{~nm}$ emission decay kinetics was measured for the doubly doped $\mathrm{LuF}_{3}: \mathrm{Gd} 1 \% \mathrm{Nd} 1 \%$ sample under excitation at 306 into $\mathrm{Gd}^{3+}{ }^{6} \mathrm{P}$ multiplet or at $275 \mathrm{~nm}$ into $\mathrm{Gd}^{3+}{ }^{6} \mathrm{I}$ 
multiplet, a curve with around $7 \mathrm{~ms}$ decay time was obtained (figure 14). The value is again close to that of $\mathrm{Gd}^{3+}$, even if the $\mathrm{Nd}^{3+}$ emission is monitored. The slight decay acceleration with respect to the $\mathrm{Gd}^{3+}$ emission is again cause by the energy transfer itself. Unlike for the $\mathrm{Gd}, \mathrm{Nd}$ doubly-doped BaLuYF sample (figure 7c), no component close to $\mathrm{Nd}^{3+}$ emission is observed. The fast 670 us component spreads over only some 8 channels and its physical meaning is doubtful. Further research is necessary to clarify these observations.

\section{Conclusions}

The Gd-doped, Nd-doped and doubly Gd,Nd-codoped $\mathrm{BaLu}_{1.2} \mathrm{Y}_{0.8} \mathrm{~F}_{8}$ and $\mathrm{LuF}_{3}$ VUV scintillation crystals were successfully grown by micro-pulling-down method. Positive effect of Gd-codoping on overall scintillation efficiency in the VUV region was confirmed for the Nd-doped $\mathrm{BaLu}_{1.2} \mathrm{Y}_{0.8} \mathrm{~F}_{8}$ crystals. This effect is due to an energy transfer from the $\mathrm{Gd}^{3+}$ to $\mathrm{Nd}^{3+}$ ions. . On the other hand, the light yield under alpha-ray excitation was significantly degraded probably due to introduction of slow components in scintillation decay process by Gd codoping. An unwanted back-transfer from $\mathrm{Nd}^{3+}$ to $\mathrm{Gd}^{3+}$ ions was confirmed as well.Similar phenomena were observed also for the $\mathrm{LuF}_{3}$ scintillation crystals, however, no improvement in the overall scintillation efficiency in the VUV region was confirmed, though it was confirmed for the alpha-ray excited light yield. Further research involving time-resolved spectroscopy in VUV region is necessary to clarify these complicated processes.

In both $\mathrm{BaLu}_{1.2} \mathrm{Y}_{0.8} \mathrm{~F}_{8}$ and $\mathrm{LuF}_{3}$ Gd-only-doped crystals an unusual $\mathrm{Gd}^{3+} 4 \mathrm{f}-4 \mathrm{f}$ luminescence at $147 \mathrm{~nm}$ was observed for the first time and was ascribed to the ${ }^{2} \mathrm{G}(0)_{7 / 2} \rightarrow{ }^{8} \mathrm{~S}_{7 / 2}$ transition. This luminescence transition is most probably involved in the energy transfer from the $\mathrm{Gd}^{3+}$ to the $\mathrm{Nd}^{3+}$ ions in both materials.

\section{Acknowledgments}

This work is partially supported by

(i) Japan Society for the Promotion of Science (JSPS)

(ii) Development of Systems and Technology for Advanced Measurement and Analysis (SENTAN), Japan Science and Technology Agency (JST),

(iii) Adaptable and Seamless Technology Transfer Program through Target-driven R\&D (A-STEP), JST,

(iv)Health Labour Sciences Research Grant, The Ministry of Health Labour and Welfare,

(v) The New Energy and Industrial Technology Development Organization (NEDO),

(vi) Supporting Industry program, Ministry of Economy, Trade and Industry

(vii) the Association for the Progress of New Chemical Technology

(viii) Czech MEYS KONTAKT LH14266 and

(ix) DESY II-20100033 project 
In addition, we would like to thank following persons for their support: Mr. Yoshihiro Nakamura of Institute of Multidisciplinary Research for Advanced Materials (IMRAM), Tohoku University, and Mr. Hisakazu Nagato, Mr. Hiroshi Uemura, Ms. Keiko Toguchi, Ms. Megumi Sasaki, Ms. Yuka Takeda and Ms. Kuniko Kawaguchi of IMR, Tohoku University. Dr. Aleksei Kotlov of Hasylab, DESY is also acknowledged for technical help with measurements at Superlumi station.

\section{References}

1. P. Schotanus, P. Dorenbos, C. W. E. van Eijk, and R. W. Holander, Recent developments in scintillator research, IEEE Trans. Nucl. Sci. 36 (1989) 132 - 136.

2. C. W. E. van Eijk, P. Dorenbos, R. Visser, $\mathrm{Nd}^{3+}$ and $\mathrm{Pr}^{3+}$ Doped Inorganic Scintillators, IEEE Trans. Nucl. Sci. 41 (1994) 738-741.

3. P. Dorenbos, C. W. E. van Eijk, R. W. Hollander, and P. Schotanus, Scintillation properties of $\mathrm{Nd}^{3+}$ doped $\mathrm{LaF}_{3}$ crystals, IEEE T. Nucl. Sci. 37 (1993) 119-123.

4. R. T. Wegh, A. Meijerink, Spin-allowed and spin-forbidden $4 \mathrm{f}^{\mathrm{n}}-4 \mathrm{f}^{\mathrm{n}-1} 5 \mathrm{~d}$ transitions for heavy lanthanides in fluoride hosts, Phys. Rev. B 60 (1999) 10820 - 10830.

5. R. Chechik and A. Breskin, Advances in Gaseous Photomultipliers, Nucl. Instrum. Meth. 595 (2008) $116-131$.

6. S. Kurosawa, K. Taniue, H. Sekiya et al., Development of a new imaging device using a VUV scintillator and a gas photomultiplier with a m-PIC and GEM, J. Inst. 7 (2012) C03013 (1) - C03013 (9).

7. G. Blasse, B.C. Grabmaier, Luminescent materials, Springer-Verlag, Berlin-Heidelberg, 1994.

8. H. Sekiya, C. Ida, H. Kubo et al., Developments of a large area VUV sensitive gas PMT with GEM/mPIC, J. Inst. 4 (2009) P11006(1)-P11006(7).

9. J. Pejchal, M. Nikl, K. Fukuda, N. Kawaguchi, T. Yanagida, Y. Yokota, A. Yoshikawa, V. Babin, Luminescence mechanism in doubly doped $\mathrm{LaF}_{3}: \mathrm{Er}$, Nd VUV scintillator, IEEE Transactions on Nuclear Science 57 (2010) 1196-1199.

10. S. Kurosawa, T. Yanagida, J. Pejchal et al., Evaluation of $\mathrm{Nd}: \mathrm{BaY}_{2} \mathrm{~F}_{8}$ for VUV scintillator, 
Radiation Measurements 55 (2013) 108-111

11. J. Pejchal, M. Nikl, K. Fukuda, N. Kawaguchi, T. Yanagida, Y. Yokota, A. Yoshikawa, V. Babin, Doubly doped $\mathrm{BaY}_{2} \mathrm{~F}_{8}: E r, \mathrm{Nd}$ VUV scintillator, Radiation Measurements 45 (2010) 265- 267.

12. J. Pejchal et al., Luminescence and scintillation properties of VUV scintillation crystals based on Lu-admixed $\mathrm{BaY}_{2} \mathrm{~F}_{8}$, IEEE Trans. Nucl. Sci. 59 (2012) 2177 - 2182.

13. J. Pejchal et al., Luminescence and scintillation properties of rare-earth-doped $\mathrm{BaLu}_{2} \mathrm{~F}_{8}$ single crystals grown by the micro-pulling-down method, Phys. Status Solidi C 9 (2012) 2243-2246.

14. T. Yanagida et al., Scintillation properties of $\mathrm{Nd}^{3+}, \mathrm{Tm}^{3+}$, and $\mathrm{Er}^{3+}$ doped $\mathrm{LuF}_{3}$ scintillators in the vacuum ultraviolet region, Nucl. Inst. Meth. Phys. Res. A 659 (2011) 258-261.

15. K. Fukuda, S. Ishizu, N. Kawaguchi, T. Suyama, T. Yanagida, Y. Yokota, M. Nik1, A. Yoshikawa, Crystal growth and optical properties of the $\mathrm{Nd}^{3+}$ doped $\mathrm{LuF}_{3}$ single crystals, Optical Materials 33 (2011) 1143-1146

16. A. Yoshikawa, T. Satonaga, K. Kamada et al., Crystal growth of Ce: $\operatorname{PrF}_{3}$ by micro-pulling-down method, J. Cryst. Growth 270 (2004) 427-432.

17. J. Pejchal, M. Nikl, F. Moretti, A. Vedda, K. Fukuda, N. Kawaguchi, T. Yanagida, Y. Yokota, A. Yoshikawa, Luminescence mechanism and energy transfer in doubly doped $\mathrm{BaY}_{2} \mathrm{~F}_{8}: \mathrm{Tm}, \mathrm{Nd}$ VUV scintillator, IOP Conf. Ser.: Mater. Sci. Eng. 15 (2010) 012018(1)-012018(8)

18. J. Martincik, S. Ishizu, K. Fukuda, T. Suyama, T. Cechak, A. Beitlerova, A. Yoshikawa, M. Nikl, Concentration dependence study of VUV-UV-visible luminescence of $\mathrm{Nd}^{3+}$ and $\mathrm{Gd}^{3+}$ in $\mathrm{LuLiF}_{4}$, Optical Materials 34 (2012) 1029-1033.

19. Zimmerer G, "SUPERLUMI: A unique setup for luminescence spectroscopy with synchrotron radiation" Radiat. Meas., 42, (2007) 859-864.

20. R. T. Wegh, H. Donker, A. Meijerink, R. J. Lamminmaki, J. Holsa, Vacuum-ultraviolet spectroscopy and quantum cutting for $\mathrm{Gd}^{3+}$ in $\mathrm{LiYF}_{4}$, Physical Review B 56 (1997) 13841-13848.

21. A. Meijerink, private communication

22. W. T. Carnall, G. L. Goodman, K. Rajnak, R. S. Rana, A systematic analysis of the spectra of the 
lanthanides into single crystal $\mathrm{LaF}_{3}$, Journal of Chemical Physics 90 (1989) 3443-3457

List of figure captions:

Figure 1. Radioluminescence spectra in the VUV/UV region for the Gd1\%, Nd1\% and $\operatorname{Gd} 1 \% \mathrm{Nd} 1 \%$ BaLuYF crystals compared with that for the $\mathrm{LaF}_{3}: \mathrm{Nd}$ reference crystal.

Figure 2. Radioluminescence spectra in the VUV/UV region for the $\mathrm{Nd} 5 \%, \mathrm{Gd} 5 \% \mathrm{Nd} 5 \%$ and $\mathrm{Gd} 20 \% \mathrm{Nd} 5 \%$ BaLuYF crystals compared with that for the $\mathrm{LaF}_{3}: \mathrm{Nd}$ reference crystal.

Figure 3. Emission spectrum of BaLuYF:Gd5\% crystal under $120 \mathrm{~nm}$ excitation.

Figure 4. Excitation spectrum of the $\mathrm{Nd}^{3+} 5 \mathrm{~d}-4 \mathrm{f}$ luminescence at $185 \mathrm{~nm}$ for BaLuYF:Nd1\% sample.

Figure 5. Comparison of the pulse-height spectra under ${ }^{241} \mathrm{Am} 5.5 \mathrm{MeV}$ alpha-ray excitation for the $\mathrm{Nd} 1 \%, \mathrm{Nd} 5 \%, \mathrm{Gd} 1 \% \mathrm{Nd} 1 \%$ and $\mathrm{Gd} 5 \% \mathrm{Nd} 5 \%$ BaLuYF samples together with the $\mathrm{LaF}_{3}: \mathrm{Nd} 8 \%$ reference sample.

Figure 6. The comparison of the $\mathrm{Nd}^{3+} 5 \mathrm{~d}-4 \mathrm{f}$ emission spectrum for the BaLuYF:Nd1\% crystal with the transmittance spectrum for the BaLuYF:Gd20\% crystal.

Figure 7a. Decay kinetics of the $\mathrm{Gd}^{3+}{ }^{6} \mathrm{P}_{7 / 2} \rightarrow{ }^{8} \mathrm{~S}_{7 / 2}$ transition at $311 \mathrm{~nm}$ under $306 \mathrm{~nm}$ direct excitation for the Gd1\% BaLuYF:Gd1\% sample.

Figure 7b. Decay kinetics of the $\mathrm{Nd}^{3+}$ emission at $360 \mathrm{~nm}$ under $275 \mathrm{~nm}$ excitation for the BaLuYF:Nd1\%.

Figure 7c. Decay kinetics of the $\mathrm{Nd}^{3+}$ emission at $360 \mathrm{~nm}$ under $275 \mathrm{~nm}$ excitation for the BaLuYF:Gd1\%Nd1\%.

Figure 8 . The schematics of the luminescence mechanism of the doubly-doped BaLuYF:Gd,Nd crystal.

Figure 9. Radioluminescence spectra in the VUV/UV region for the Gd1\%, Nd1\% and $\mathrm{Gd} 1 \% \mathrm{Nd} 1 \%$ $\mathrm{LuF}_{3}$ crystals compared with that for the $\mathrm{LaF}_{3}: \mathrm{Nd}$ reference crystal. 
Figure 10. Emission spectrum of $\mathrm{LuF}_{3}: \mathrm{Gd} 1 \%$ crystal under $120 \mathrm{~nm}$ excitation.

Figure 11. Excitation spectrum of the $\mathrm{Nd}^{3+} 5 \mathrm{~d}-4 \mathrm{f}$ luminescence at $178 \mathrm{~nm}$ for $\mathrm{LuF}_{3}: \mathrm{Nd} 1 \%$ sample.

Figure 12. The comparison of the $\mathrm{Nd}^{3+} 5 \mathrm{~d}-4 \mathrm{f}$ emission spectrum for the $\mathrm{LuF}_{3}: \mathrm{Nd} 1 \%$ crystal with the transmittance spectrum for the $\mathrm{LuF}_{3}: \mathrm{Gd} 5 \% \mathrm{Nd} 5 \%$ crystal.

Figure 13. Comparison of the pulse-height spectra under ${ }^{241} \mathrm{Am} 5.5 \mathrm{MeV}$ alpha-ray excitation for the $\mathrm{Nd} 1 \%$, and $\mathrm{Gd} 1 \% \mathrm{Nd} 1 \% \mathrm{LuF}_{3}$ samples together with the $\mathrm{LaF}_{3}: \mathrm{Nd} 8 \%$ reference sample.

Figure 14. Decay kinetics of the $\mathrm{Nd}^{3+}$ emission at $360 \mathrm{~nm}$ under $275 \mathrm{~nm}$ excitation for the $\mathrm{LuF}_{3}: \mathrm{Gd} 1 \% \mathrm{Nd} 1 \%$ sample. 


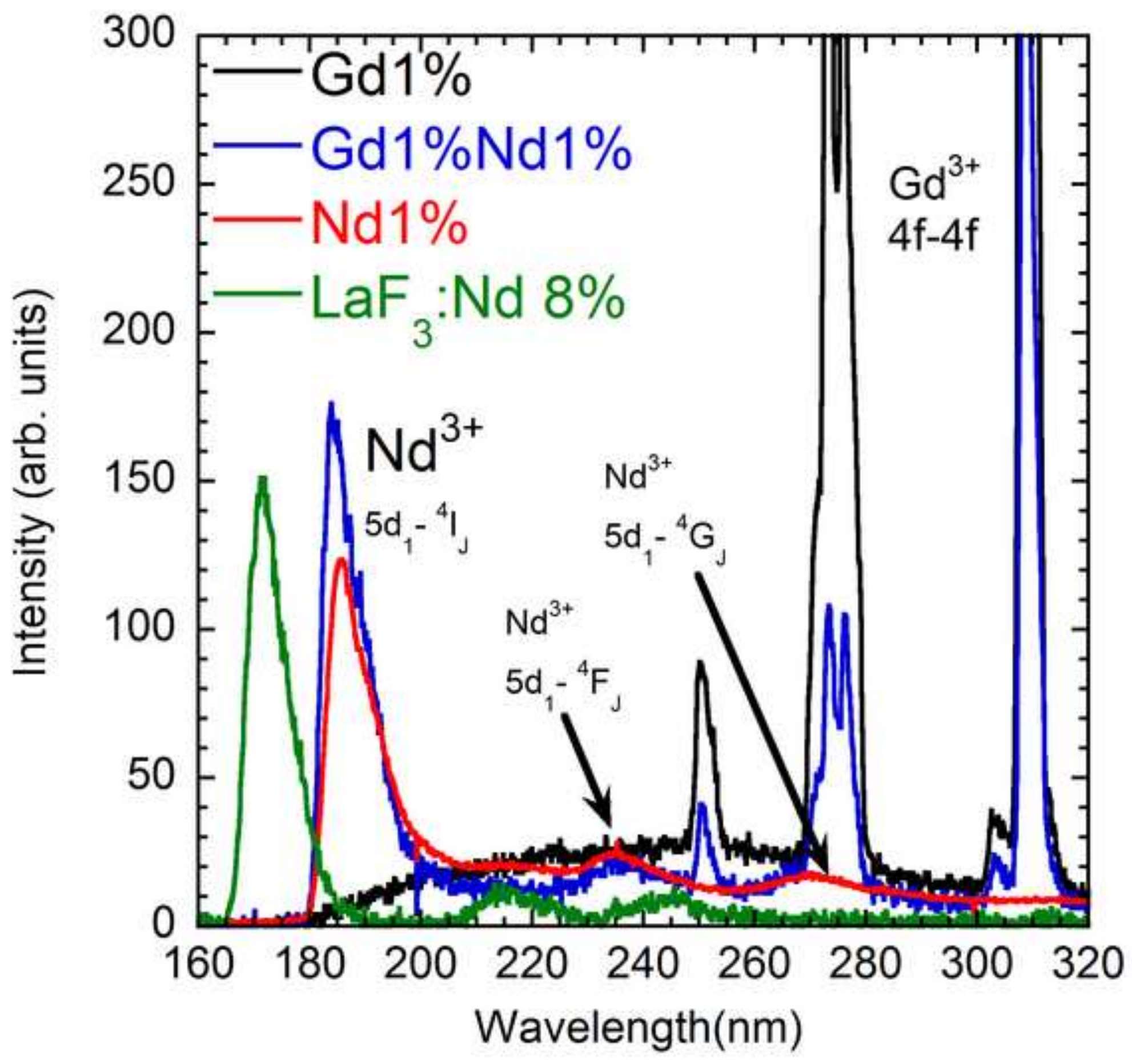




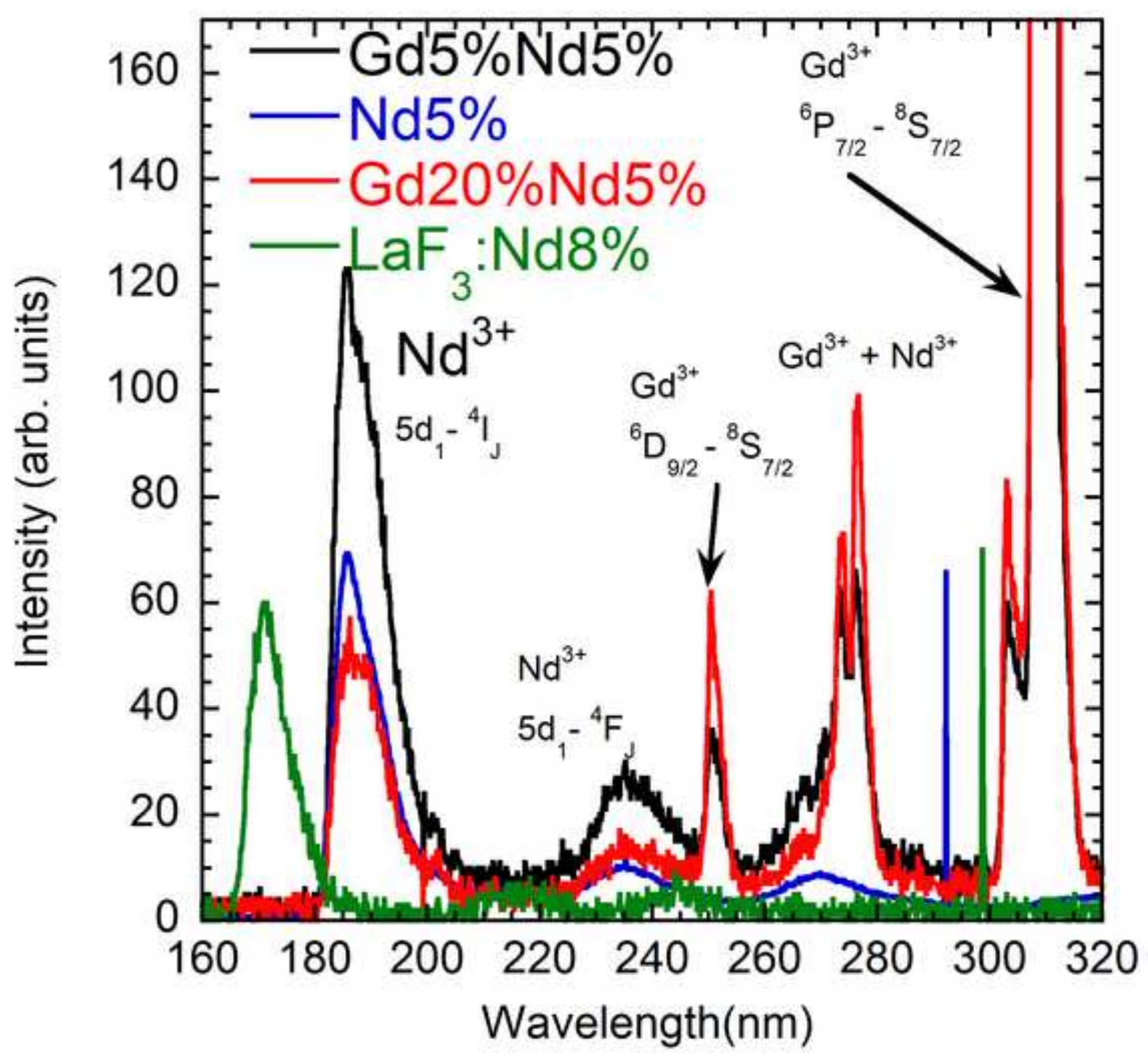




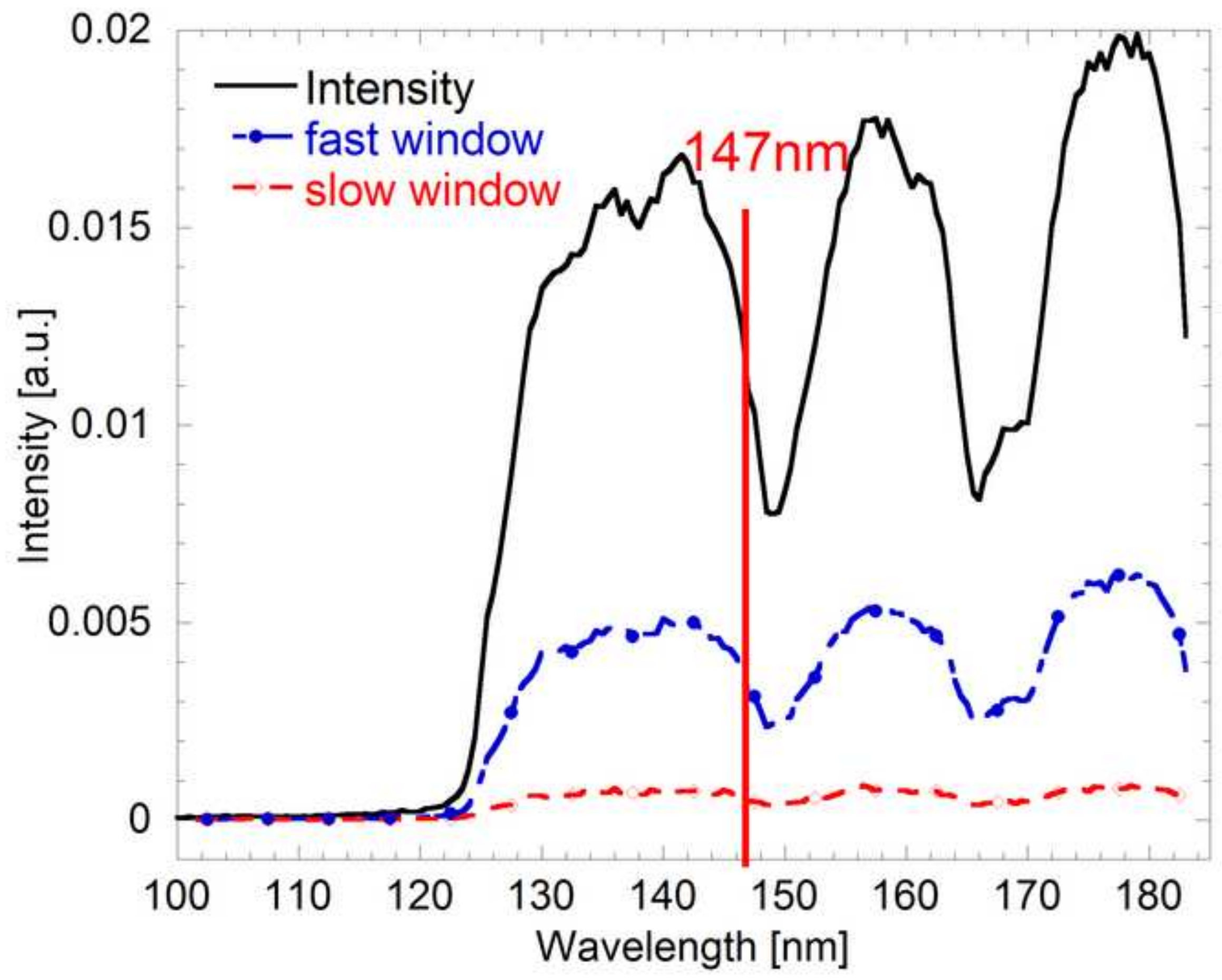




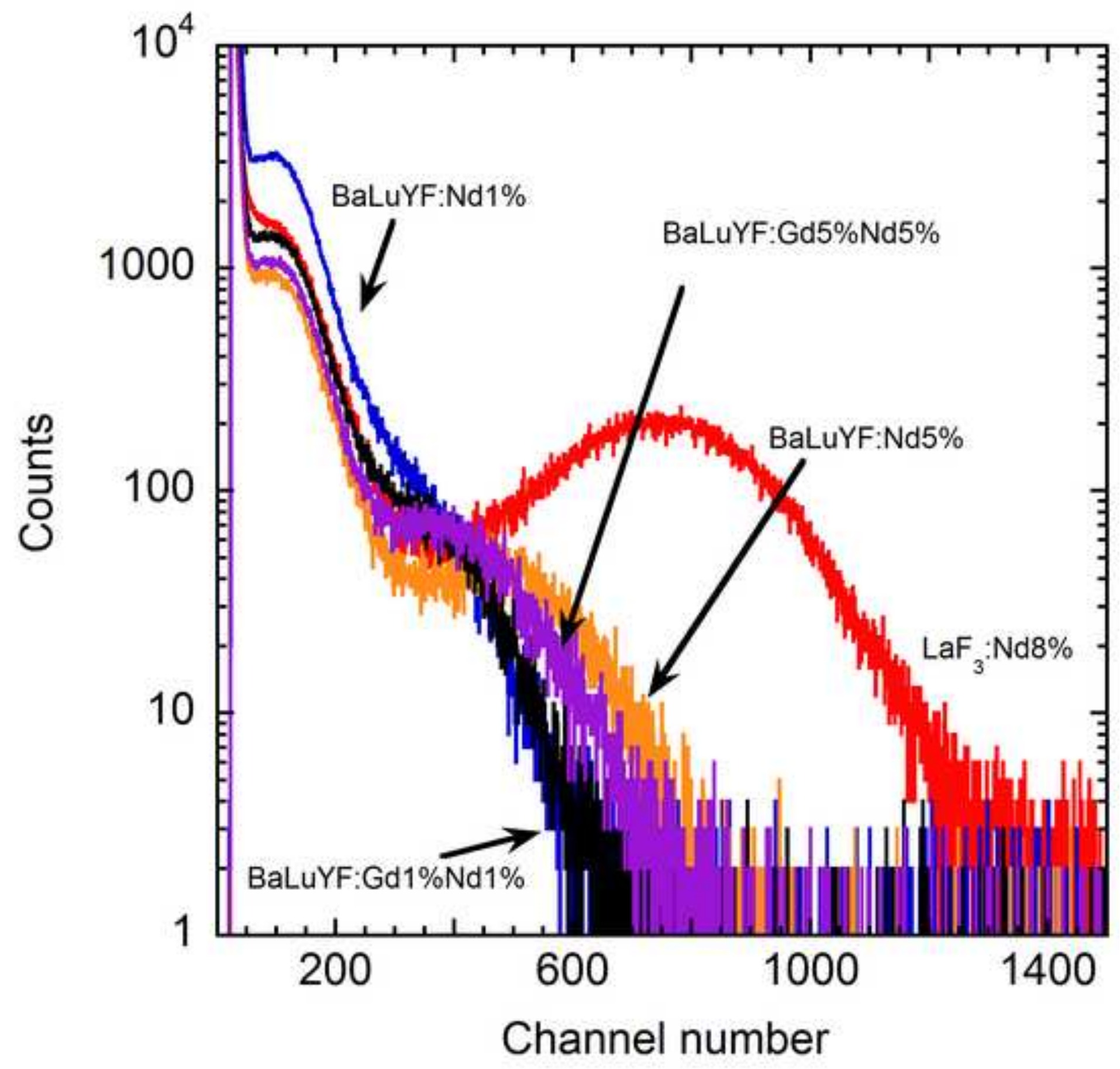




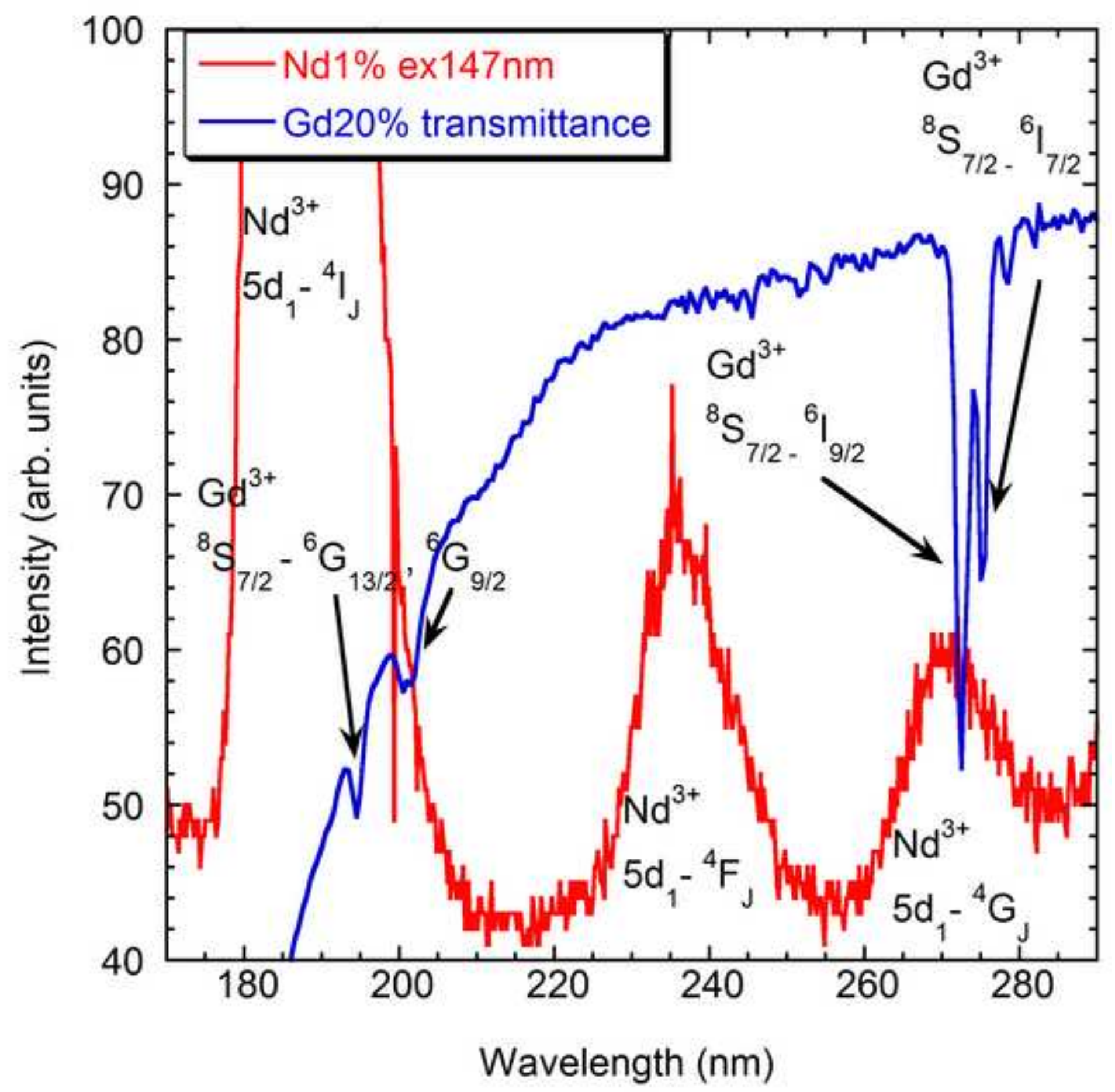




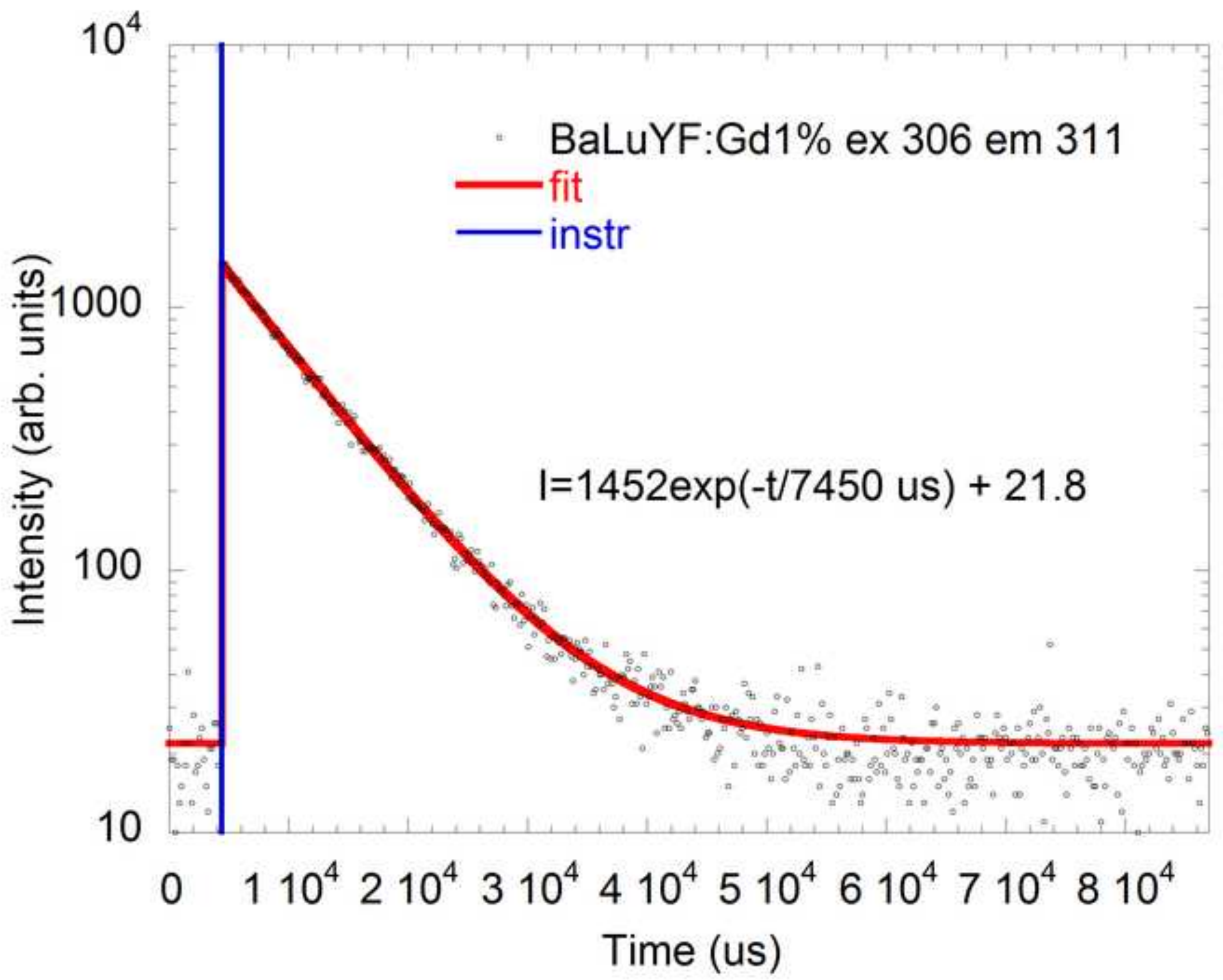




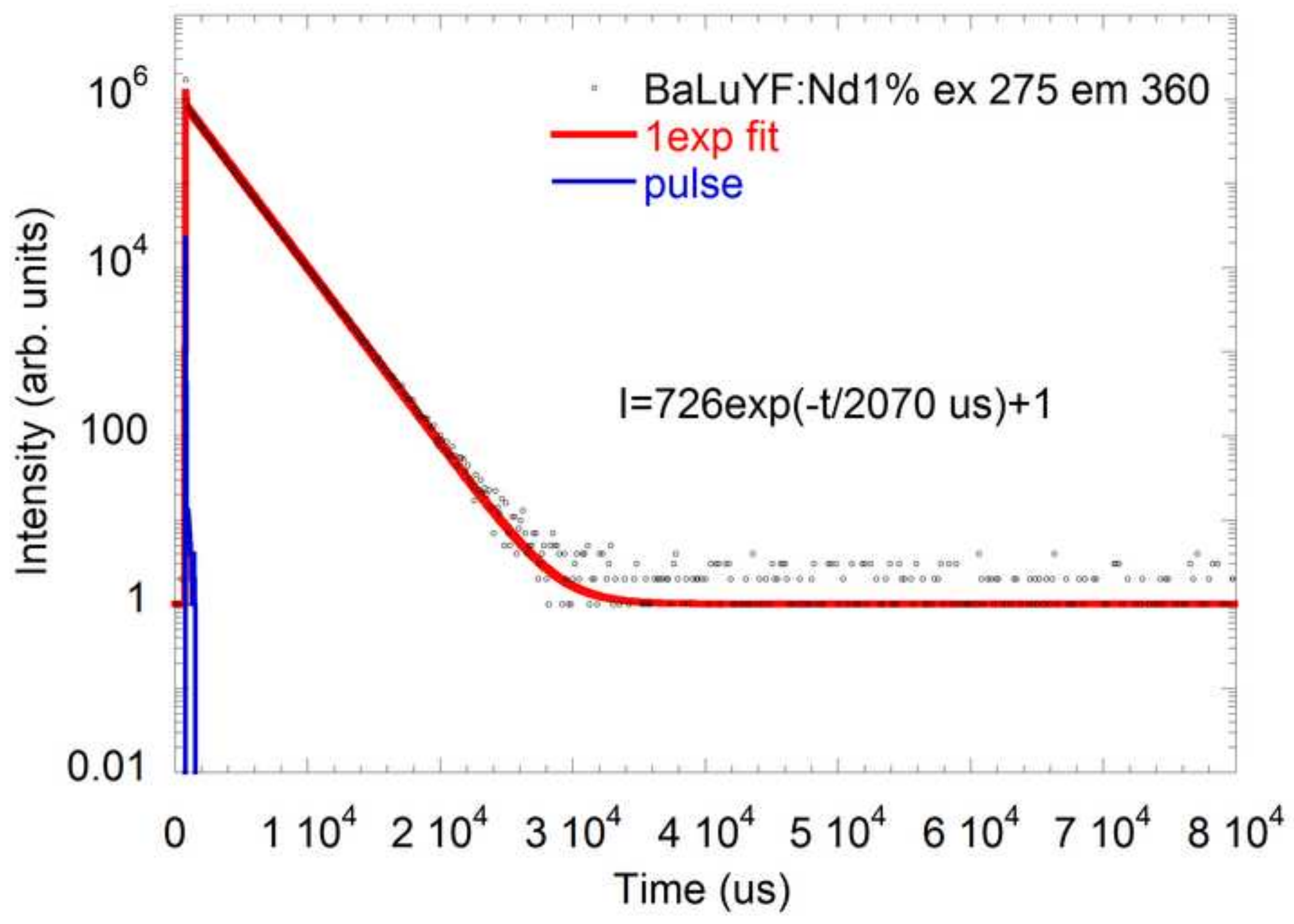




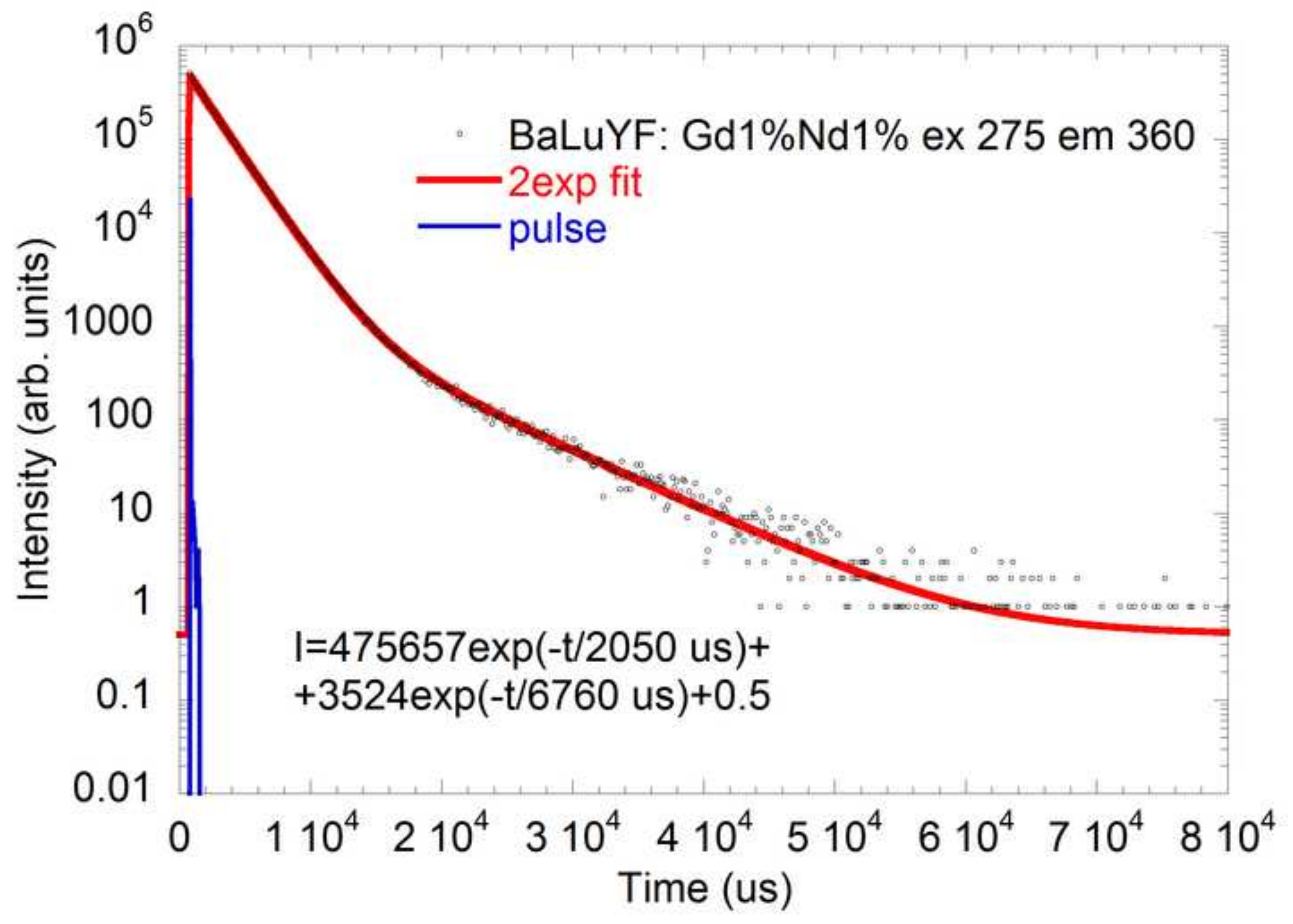



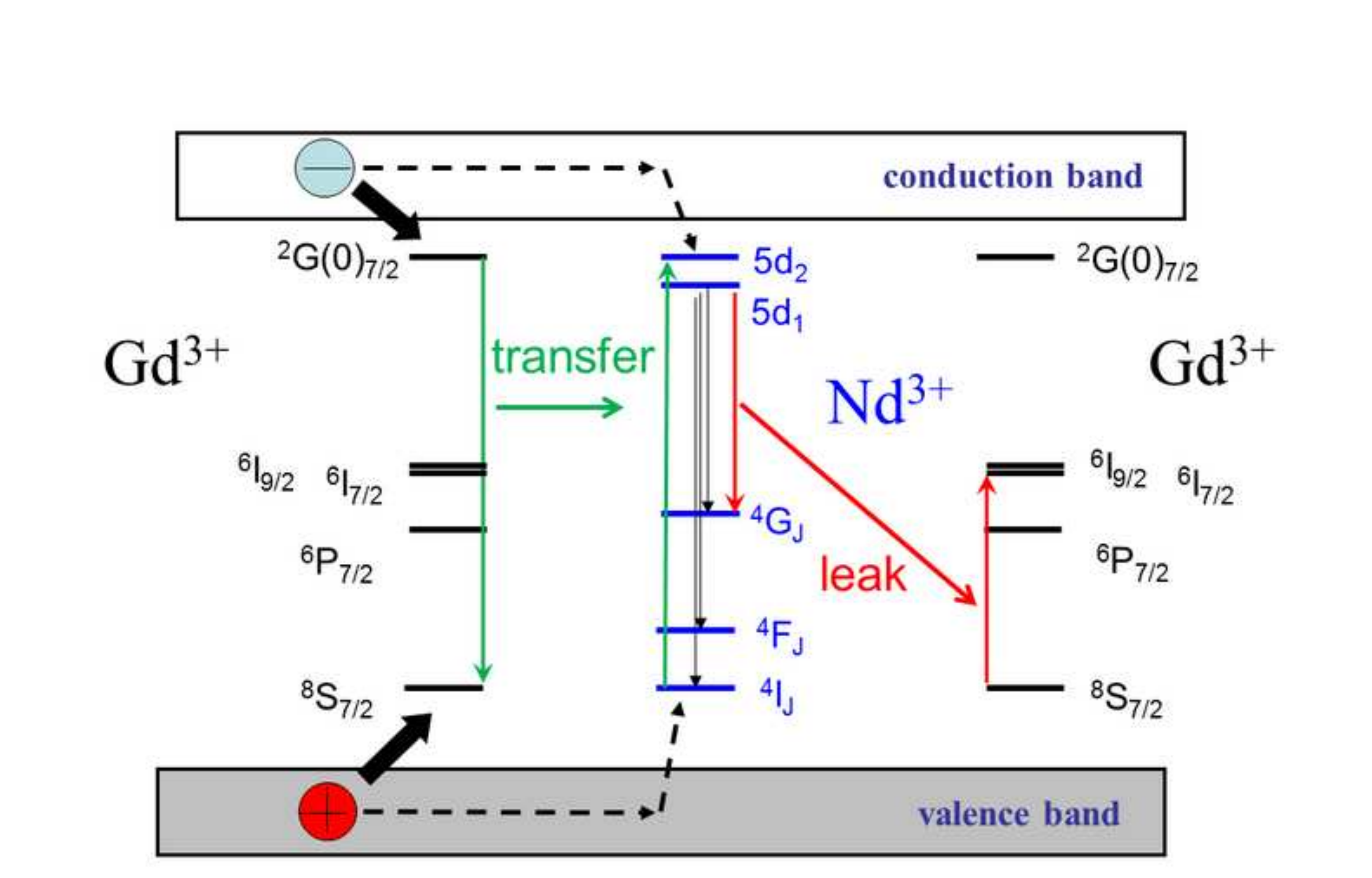

(

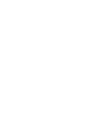
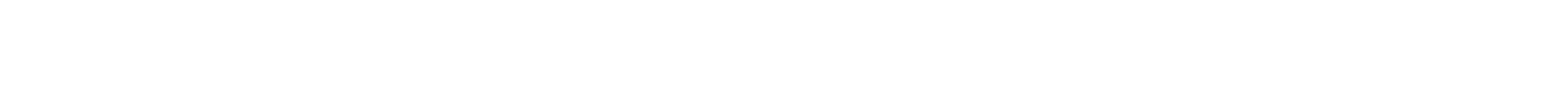


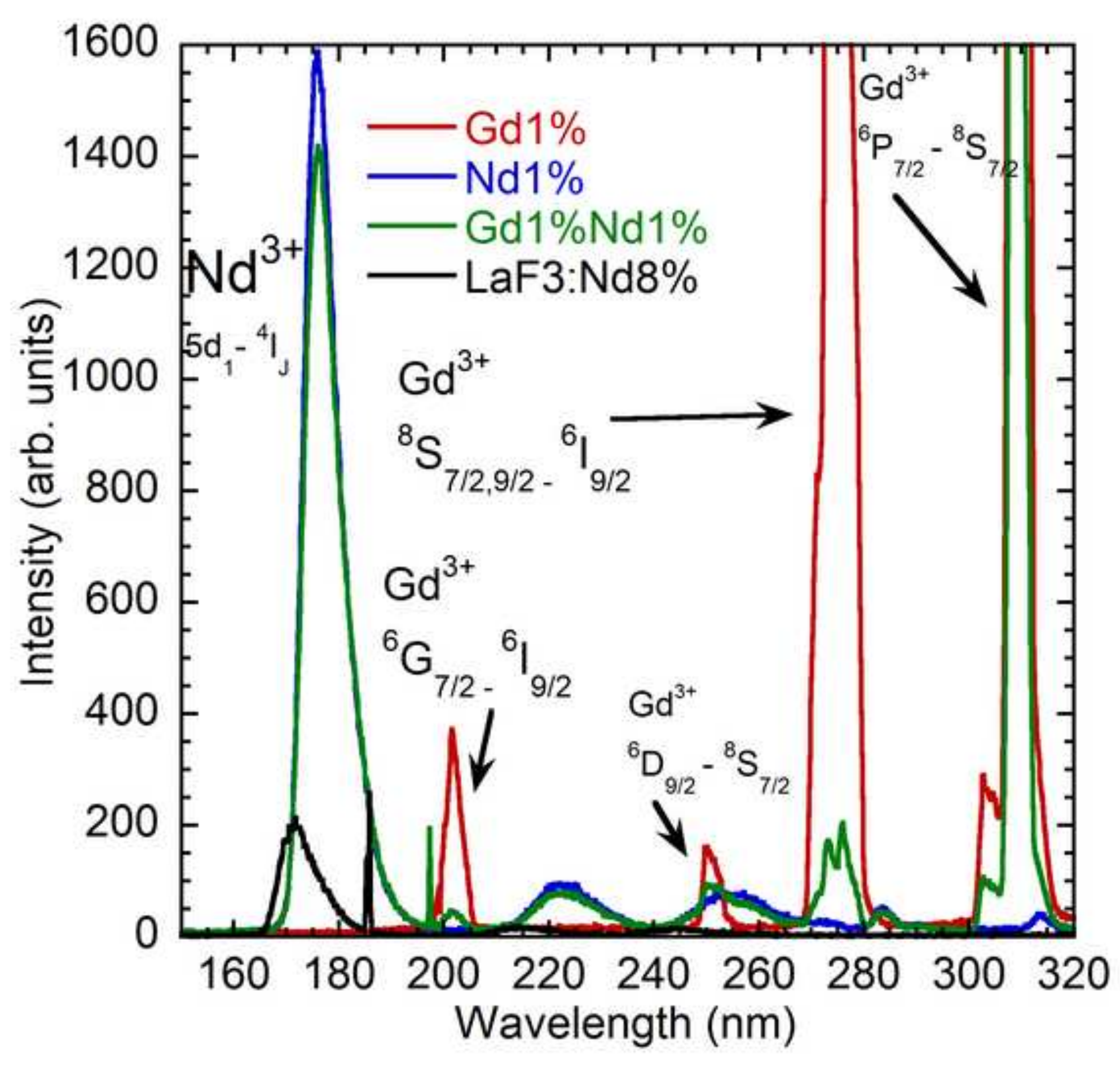




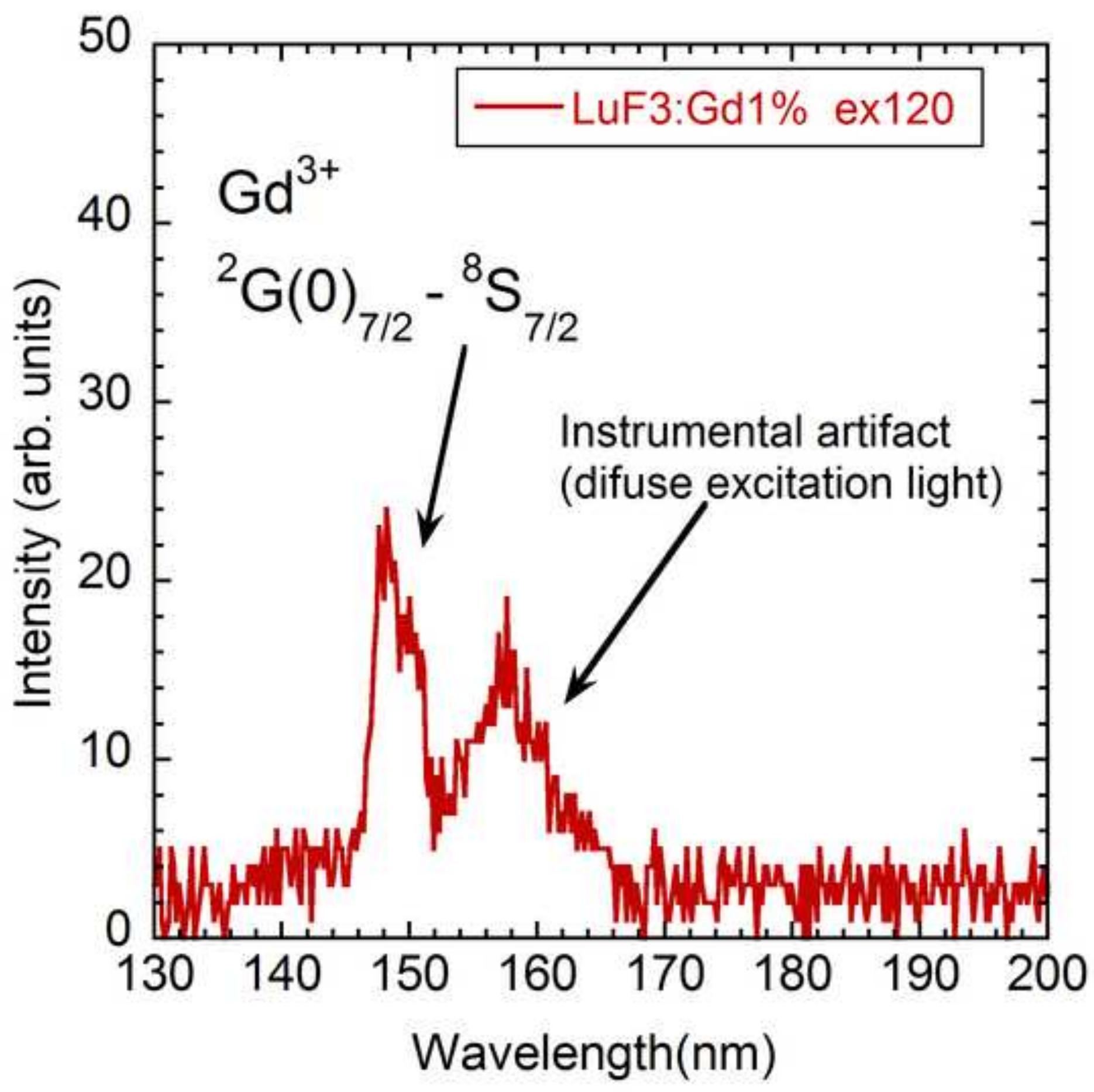




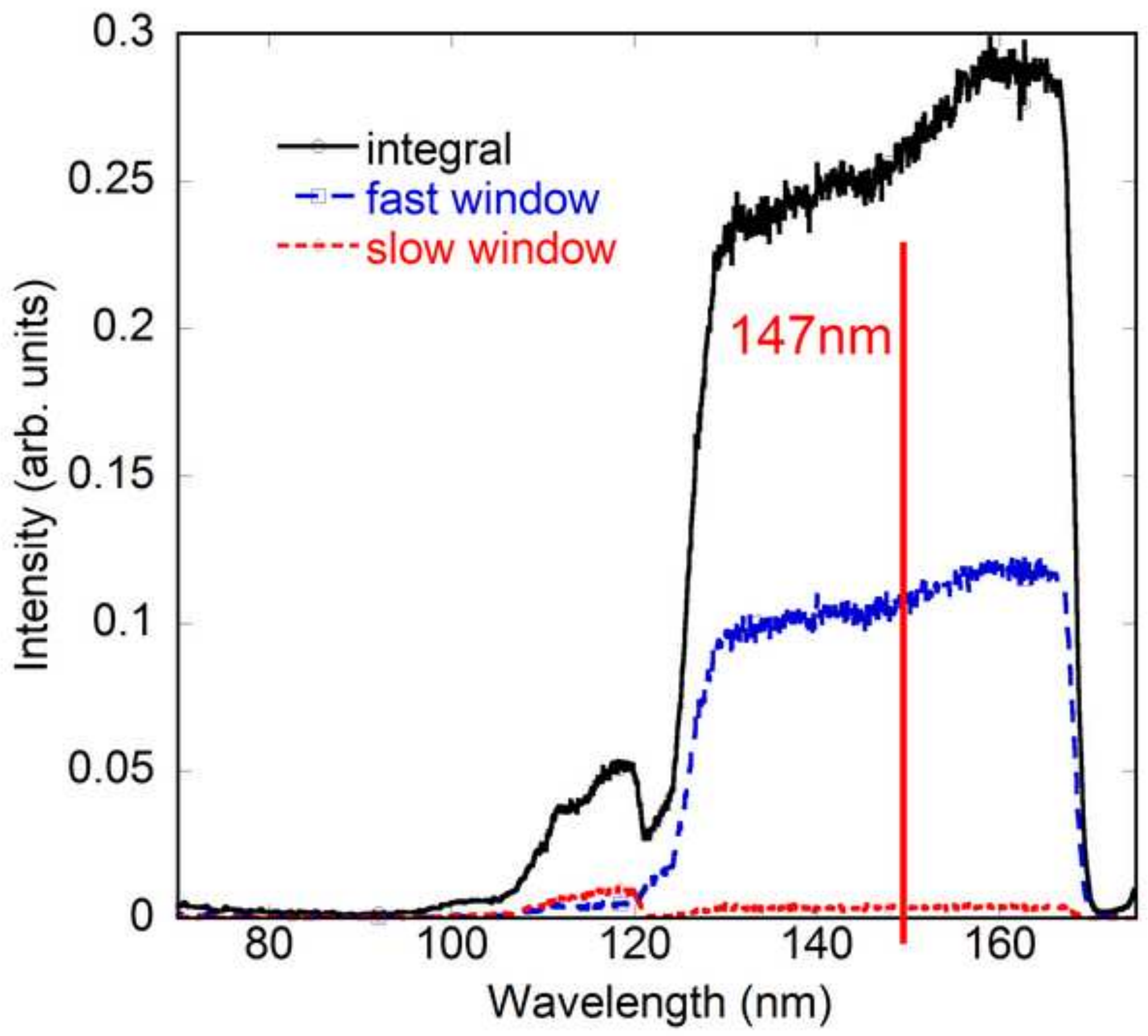




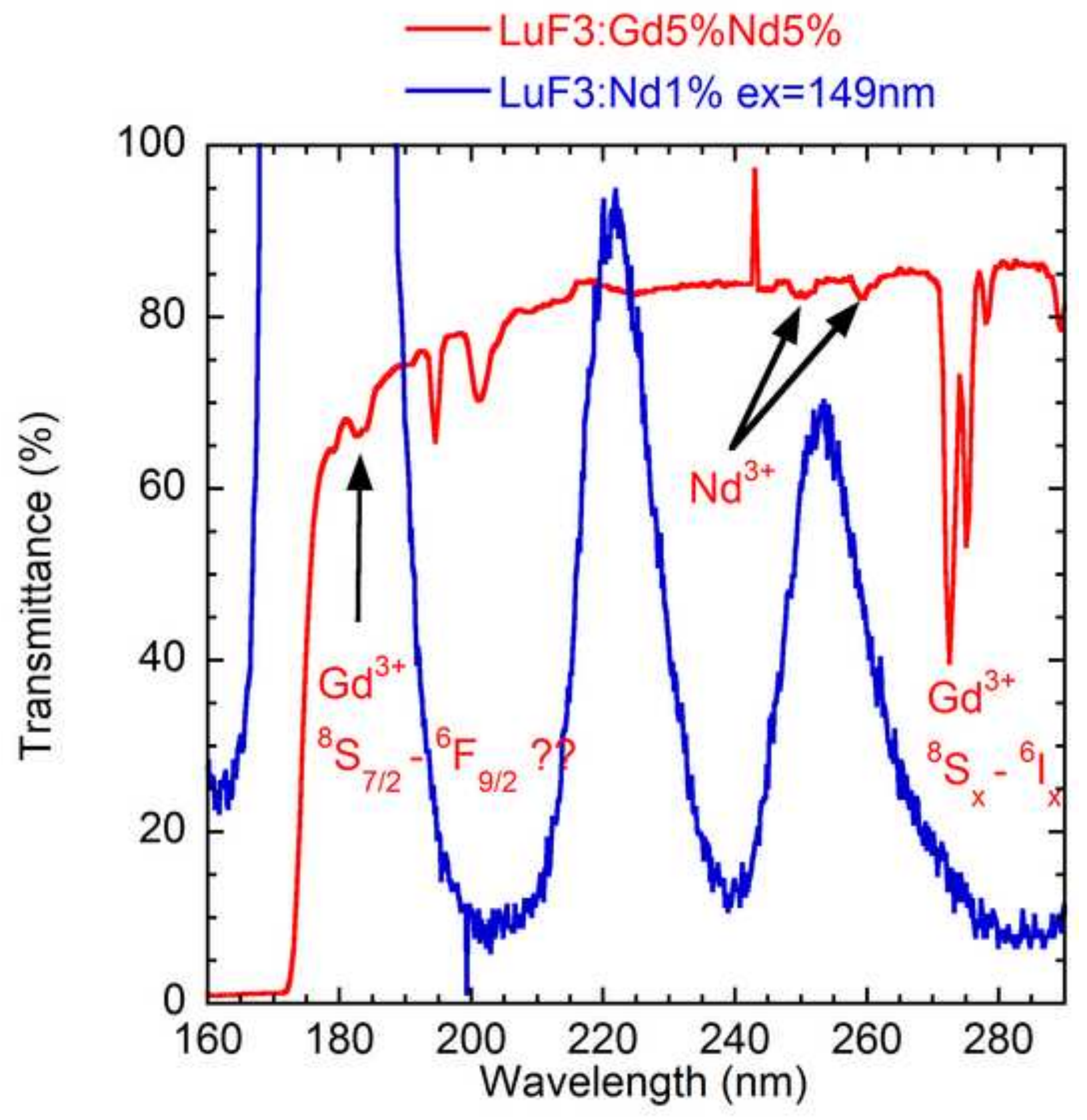

Figure12

- LuF3:Gd5\%Nd5\%

- LuF3:Nd1\% ex=149nm 


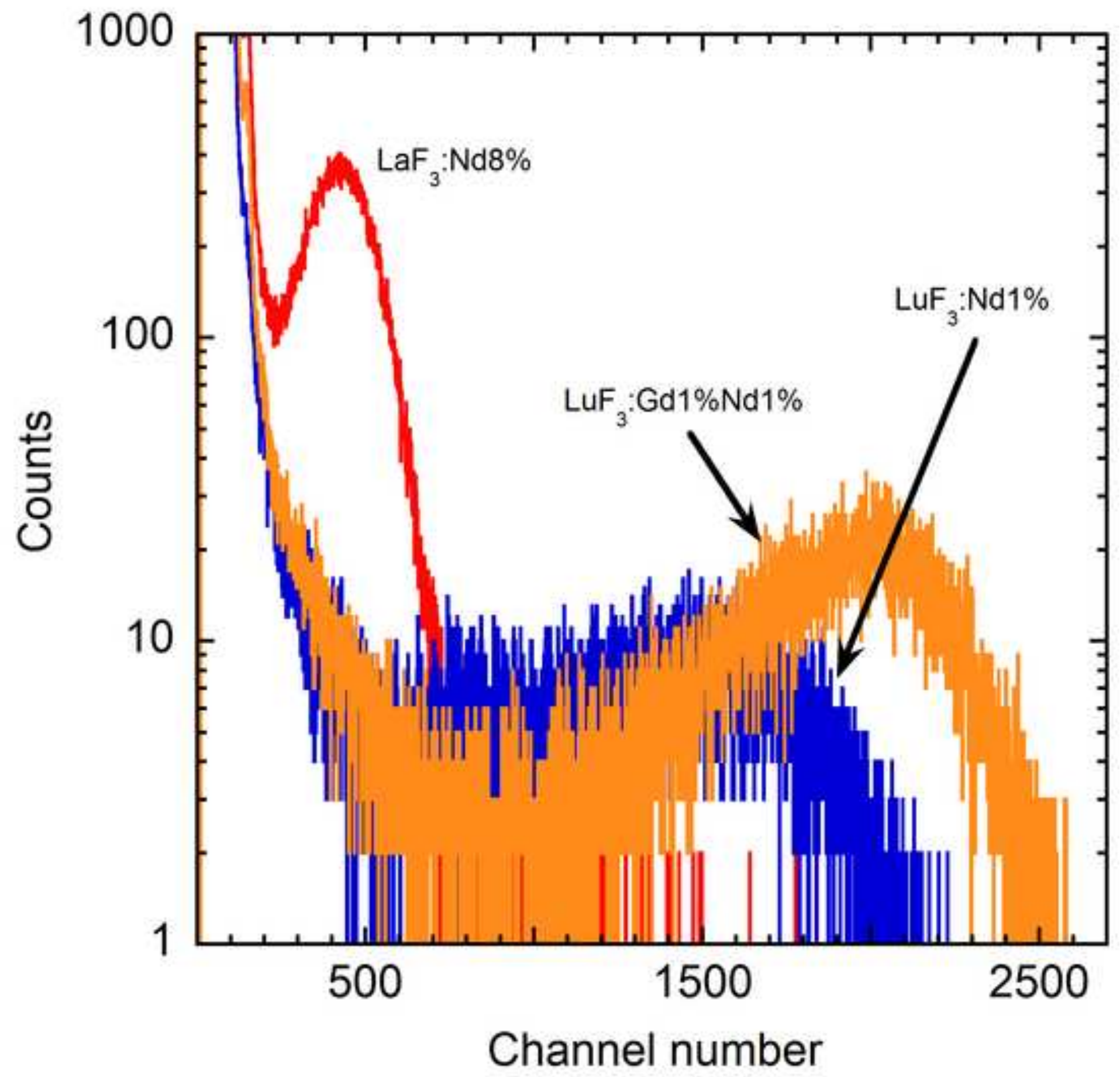




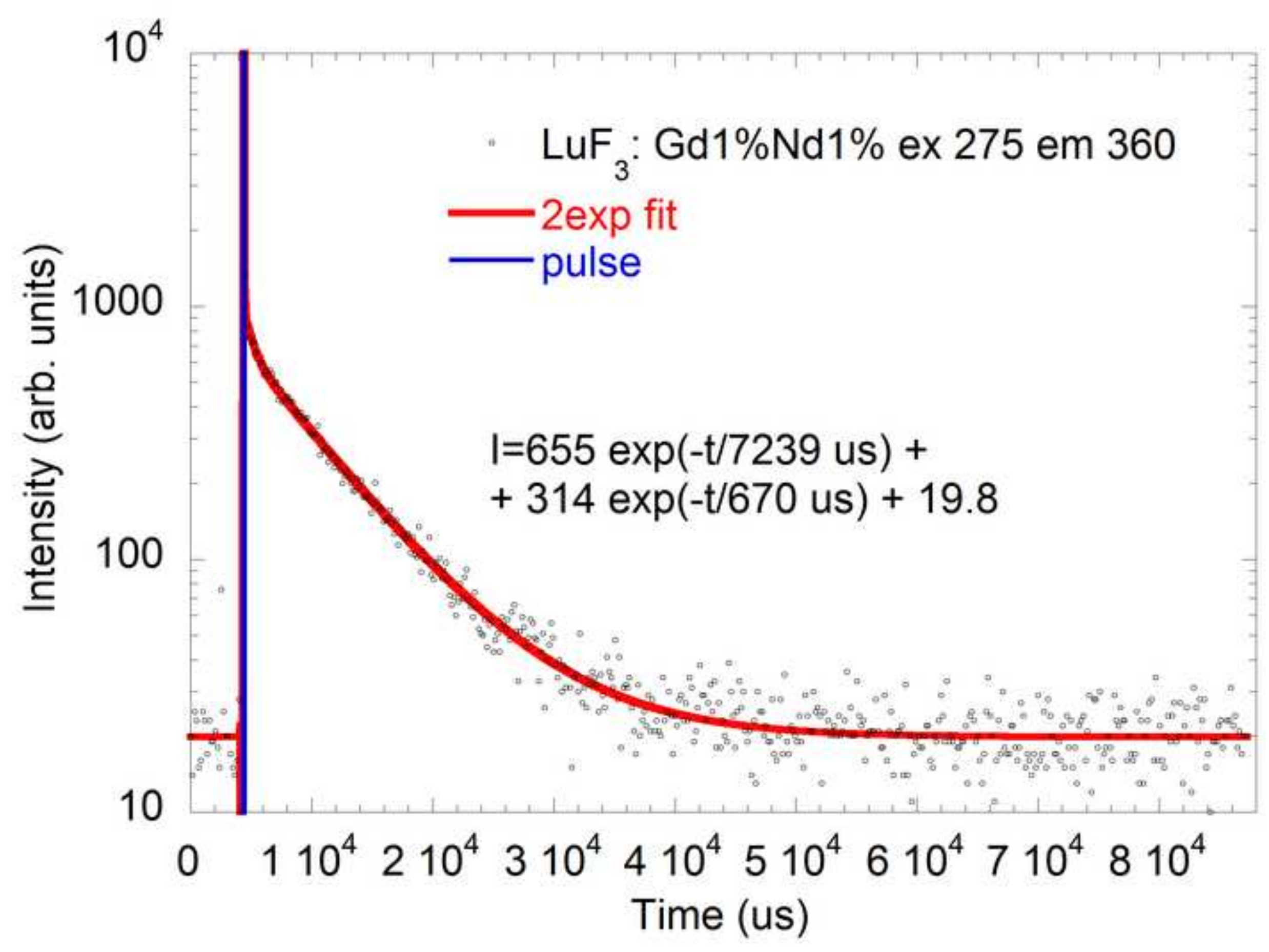

